\title{
Seismic Response of Torsionally Coupled System with Magnetorheological Dampers
}

\author{
Snehal V. Mevada and R. S. Jangid \\ Department of Civil Engineering, Indian Institute of Technology Bombay, Powai, Mumbai 400 076, India \\ Correspondence should be addressed to Snehal V. Mevada, snehalvm@iitb.ac.in
}

Received 4 July 2011; Revised 28 December 2011; Accepted 10 January 2012

Academic Editor: Andreas Kappos

Copyright ( $) 2012$ S. V. Mevada and R. S. Jangid. This is an open access article distributed under the Creative Commons Attribution License, which permits unrestricted use, distribution, and reproduction in any medium, provided the original work is properly cited.

\begin{abstract}
The seismic response of linearly elastic, idealized single-storey, one-way asymmetric building with semiactive magnetorheological (MR) dampers with clipped-optimal algorithm is investigated. The response is obtained by numerically solving the governing equations of motion. The effects of eccentricity ratio, uncoupled time period, and ratio of uncoupled torsional to lateral frequency are investigated on peak responses which include lateral, torsional and edge displacements and their acceleration counter parts, base shear, and control forces. To study the effectiveness of control system, the controlled response of asymmetric system is compared with the corresponding uncontrolled response. Further, controlled response of asymmetric system is compared with corresponding symmetric system to study the effects of torsional coupling. It is shown that the implementation of semiactive dampers reduces the deformations significantly. Also, the effects of torsional coupling on effectiveness of semiactive system are found to be more sensitive to the variation of eccentricity and torsional to lateral frequency ratio.
\end{abstract}

\section{Introduction}

Many times, most of the real structures are prone to the severe response and damage during a seismic event due to their asymmetric nature. This asymmetry in the buildings arises primarily due to uneven distribution of mass and/or stiffness of the structural components for elastic range. Due to the asymmetric nature of buildings causing the torsional deformations, they are more vulnerable to the earthquake induced damage. The prime focus of the structural engineer is to reduce the torsional response mainly by avoiding the eccentricity which is produced due to uneven mass and stiffness distribution. However, there are many limitations for avoiding the eccentricity between mass and stiffness due to stringent architectural and functional requirements and hence in such cases, implementation of supplemental energy dissipation devices proves to be an effective solution to minimize the lateral-torsional response of the buildings.

In past, many researchers have investigated the performance of seismic control aspects of lateral-torsional deformations using various techniques such as passive control namely base isolation and supplemental dampers and active control. Hejal and Chopra [1] investigated the effects of lateral-torsional couplings and demonstrated that the building response significantly depends on structural eccentricity and frequency ratio. Jangid and Datta [2] investigated that the effectiveness of base isolation for an asymmetric system reduces for higher eccentricity. Jangid and Datta [3] found that the effectiveness of multiple tuned mass dampers is overestimated by ignoring the system asymmetry. Goel [4] investigated that by implementing proper supplemental damping, edge deformations in asymmetric-plan systems can be reduced than those in the corresponding symmetric systems. Date and Jangid [5] investigated the effectiveness of active control system for an asymmetric system in controlling torsional and corner displacements and shown that effectiveness is overestimated by ignoring the effects of torsional coupling. Lin and Chopra [6] studied the effects of plan-wise distribution of nonlinear viscous and visco-elastic dampers and found that the asymmetric distribution of damping reduces the response more effectively as compared to symmetric distribution. De La Llera et al. [7] proposed the 
weak torsional balance condition for system installed with friction dampers such as to minimize the correlation between translation and rotation. Petti and De Iuliis [8] proposed a method to optimally locate the viscous dampers for torsional response control in asymmetric plan systems by using modal analysis techniques.

The semiactive control systems combine the attractive features of passive and active control systems and hence drawn the attention of many researchers, in recent past. Chi et al. [9] evaluated an asymmetric building with base isolation augmented with semiactive magnetorheological (MR) damper and found improvement in torsional behavior. Yoshida et al. [10] and Yoshida and Dyke [11] investigated the torsional response of asymmetric building using semiactive MR damper and noticed an increase of torsional response and decrease of translational response due to asymmetry. Moreover, the base torque increases and base shear decreases with an increase in eccentricity for strongly coupled system. Shook et al. [12] investigated the effectiveness of semiactive MR damper and observed that fuzzy logic controller is effective in decoupling lateral and torsional response with reduction in displacement and acceleration responses. H. N. Li and X. L. Li [13] developed an MR damper based on semi-geometric model for asymmetric building and found a greater reduction in displacement and acceleration responses compared to passive control case. Although, the above studies reflect the effectiveness of some of the semiactive systems in controlling the lateral-torsional responses, however, no specific study has been carried out to investigate the effects of torsional coupling especially by considering important system parameters on edge deformations as well as on control forces using semiactive MR dampers.

In this paper, the seismic response of idealized single storey, one-way asymmetric building, is investigated under different real earthquake ground motions. The specific objectives of the study are summarized as (i) to study the effects of torsional coupling on the effectiveness of the semiactive MR damper control system, (ii) to investigate the effectiveness of semiactive MR dampers with clippedoptimal control algorithm in controlling lateral, torsional and specifically the edge deformations, and (iii) to investigate the influence of important parameters on the effectiveness of semiactive MR dampers for asymmetric systems. The important parameters considered are eccentricity ratio of superstructure and uncoupled time period and ratio of uncoupled torsional to lateral frequency.

\section{Model of Magnetorheological Damper}

Magnetorheological (MR) dampers are the semiactive devices which use MR fluids to provide control forces and they are quite promising for civil engineering applications. They offer highly reliable operation at a modest cost and can be considered as fail-safe in the case of hardware malfunction in that they become passive dampers. MR fluids typically consist of micron-sized magnetically polarizable particles dispersed in a carrier medium such as silicon oil. When a magnetic field is applied to the fluids, particle chains

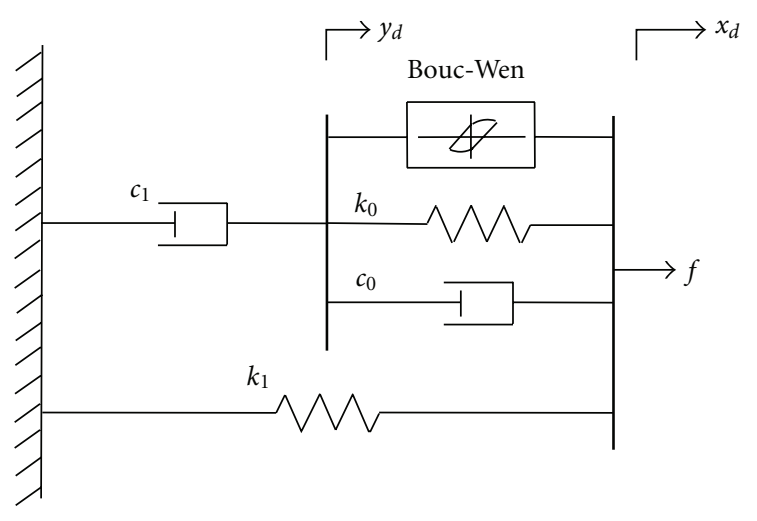

FIGURE 1: Mechanical model of the MR damper (Modified BoucWen model) [14].

form, and the fluid becomes a semisolid, exhibiting plastic behavior. MR fluids have high yield strength, low viscosity, and stable hysteretic behavior over a wide temperature range. Transition to rheological equilibrium can be achieved in a few milliseconds, providing devices with high bandwidth. MR devices are capable of generating large forces [15].

In this study, the Modified Bouc-Wen model proposed by Spencer et al. [14] as shown in Figure 1 is used. The model has shown to accurately predict the behavior of the prototype MR damper over a broad range of inputs. The equations governing the force predicted by this model is [14]

$$
\begin{aligned}
f_{i} & =\alpha_{i} z_{i}+c_{0 i}\left(\dot{x}_{d i}-\dot{y}_{d i}\right)+k_{0}\left(x_{d i}-y_{d i}\right)+k_{1}\left(x_{d i}-x_{0}\right) \\
& =c_{1 i} \dot{y}_{d i}+k_{1}\left(x_{d i}-x_{0}\right)
\end{aligned}
$$

where the evolutionary variable $z_{i}$ is governed by

$$
\begin{aligned}
\dot{z}_{i}= & -\gamma_{m}\left|\dot{x}_{d i}-\dot{y}_{d i}\right| z_{i}\left|z_{i}\right|^{n-1}-\beta_{m}\left(\dot{x}_{d i}-\dot{y}_{d i}\right)\left|z_{i}\right|^{n} \\
& +A_{m}\left(\dot{x}_{d i}-\dot{y}_{d i}\right) \\
\dot{y}_{d i}= & \frac{1}{\left(c_{0 i}+c_{1 i}\right)}\left\{\alpha_{i} z_{i}+c_{0 i} \dot{x}_{d i}+k_{0}\left(x_{d i}-y_{d i}\right)\right\} .
\end{aligned}
$$

In this model, the accumulator stiffness is represented by $k_{1}$ and the viscous damping observed at large velocities by $c_{0 i}$. A dashpot, represented by $c_{1 i}$, is included in the model to introduce the nonlinear roll-off in the force-velocity loops at low velocities, $k_{0}$ is present to control the stiffness at large velocities, and $x_{0}$ is the initial displacement of spring $k_{1}$ associated with the nominal damper force due to the accumulator.

To account for the dependence of the force on the voltage applied to the current driver and the resulting magnetic current, the suggested parameters are

$$
\begin{gathered}
\alpha_{i}=\alpha_{a}+\alpha_{b} u_{d i}, \quad c_{0 i}=c_{0 a}+c_{0 b} u_{d i}, \\
c_{1 i}=c_{1 a}+c_{1 b} u_{d i} .
\end{gathered}
$$




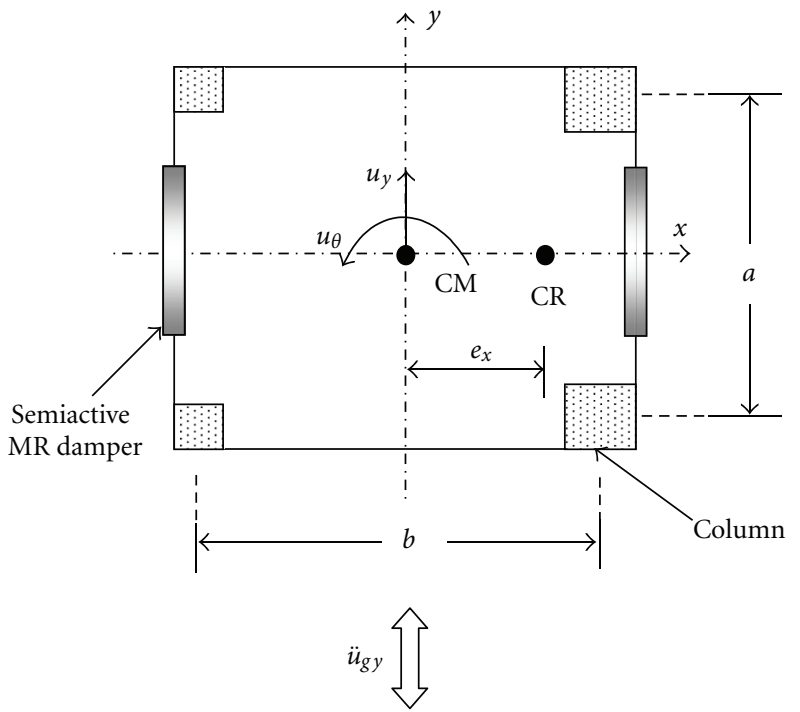

(a)

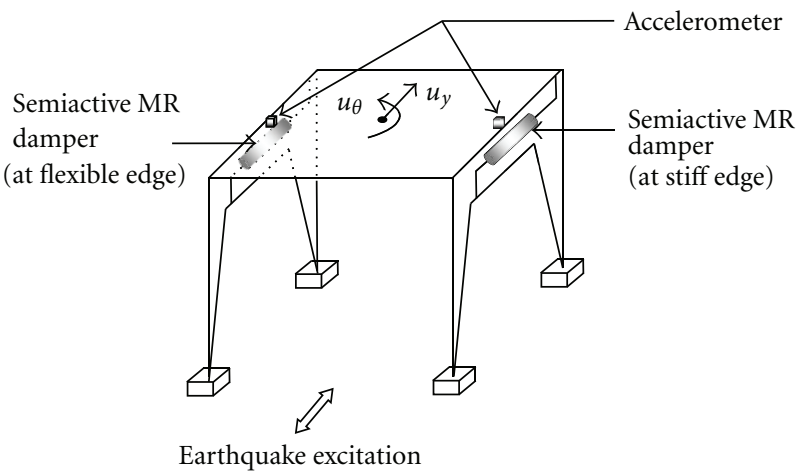

(b)

FIgURE 2: Plan and isometric view of one-way asymmetric system showing arrangement of dampers and accelerometers.

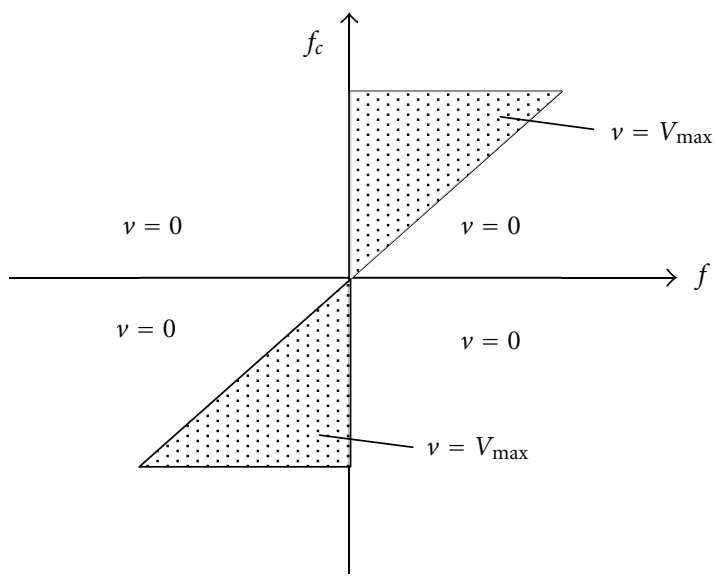

(a)

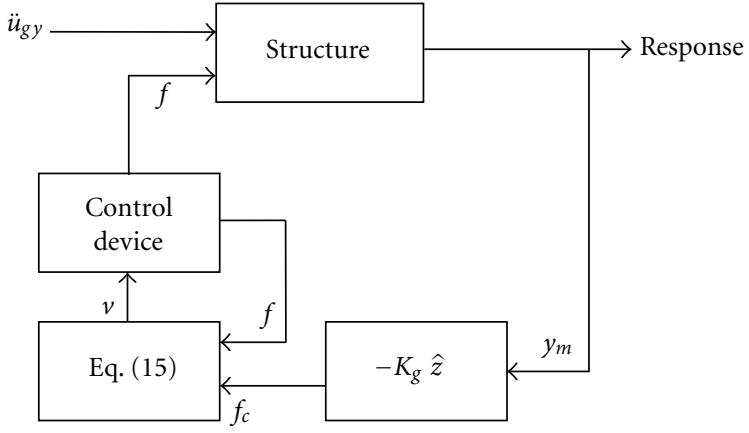

(b)

FIGURE 3: Graphical representation of clipped-optimal control algorithm [15] and semiactive control system.

In addition, the dynamics involved in the MR fluid reaching rheological equilibrium are accounted for through the first-order filter

$$
\dot{u}_{d i}=-\eta\left(u_{d i}-v_{i}\right),
$$

where $v_{i}$ is the commanded voltage sent to the current driver.

\section{Structural Model and Solution of Equations of Motion}

The system considered is an idealized one-storey building which consists of a rigid deck supported on columns as shown in Figure 2. Following assumptions are made for the structural system under consideration: (i) floor of the superstructure is assumed as rigid, (ii) force-deformation behaviour of the superstructure is considered as linear within elastic range, (iii) the structure is excited by uni-directional horizontal component of earthquake ground motion and the vertical component of earthquake motion is neglected, and (iv) the effect of time delay is neglected for control algorithm. The mass of deck is assumed to be uniformly distributed and hence centre of mass (CM) coincides with the geometrical centre of the deck. The columns are arranged in a way such that it produces the stiffness asymmetry with respect to the $\mathrm{CM}$ in one direction and hence, the centre of rigidity $(\mathrm{CR})$ is located at an eccentric distance, $e_{x}$ from $\mathrm{CM}$ in $x$-direction. The system is symmetric in $x$-direction and therefore, two degrees-of-freedom are considered for model, namely, the lateral displacement in $y$-direction, $u_{y}$ and torsional displacement, $u_{\theta}$ as represented in Figure 2. The governing equations of motion of the building model with coupled lateral and torsional degrees-of-freedom are obtained by assuming that the control forces provided by 


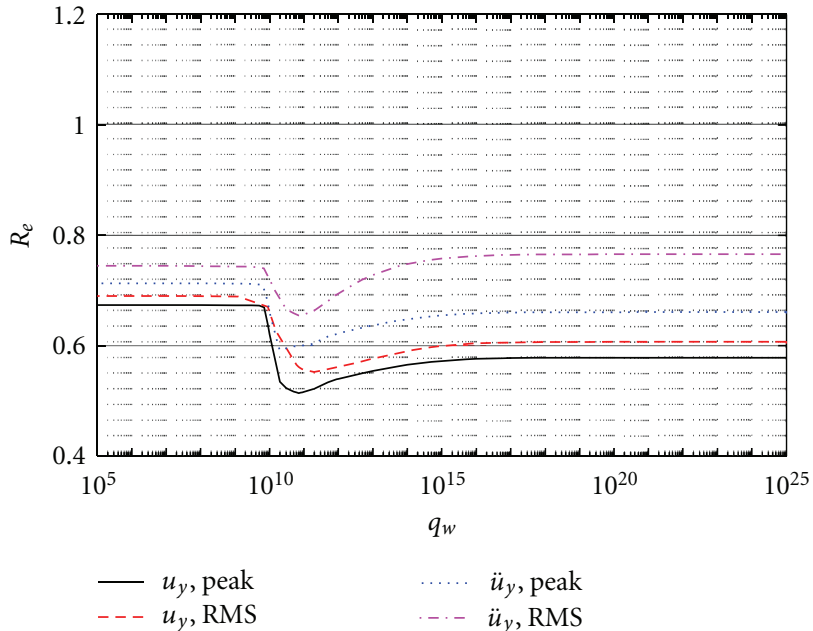

(a)

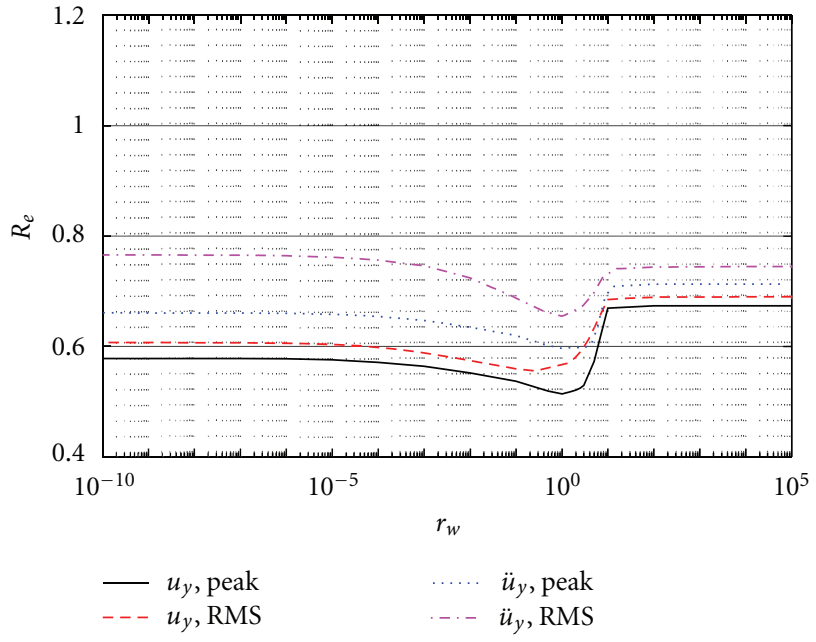

(b)

FIGURE 4: Effect of weighting parameters on response ratio, $R_{e}$ for peak and RMS responses under Imperial Valley, 1940 earthquake $\left(T_{y}=1 \mathrm{~s}\right.$, $\left.e_{x} / r=0\right)$.
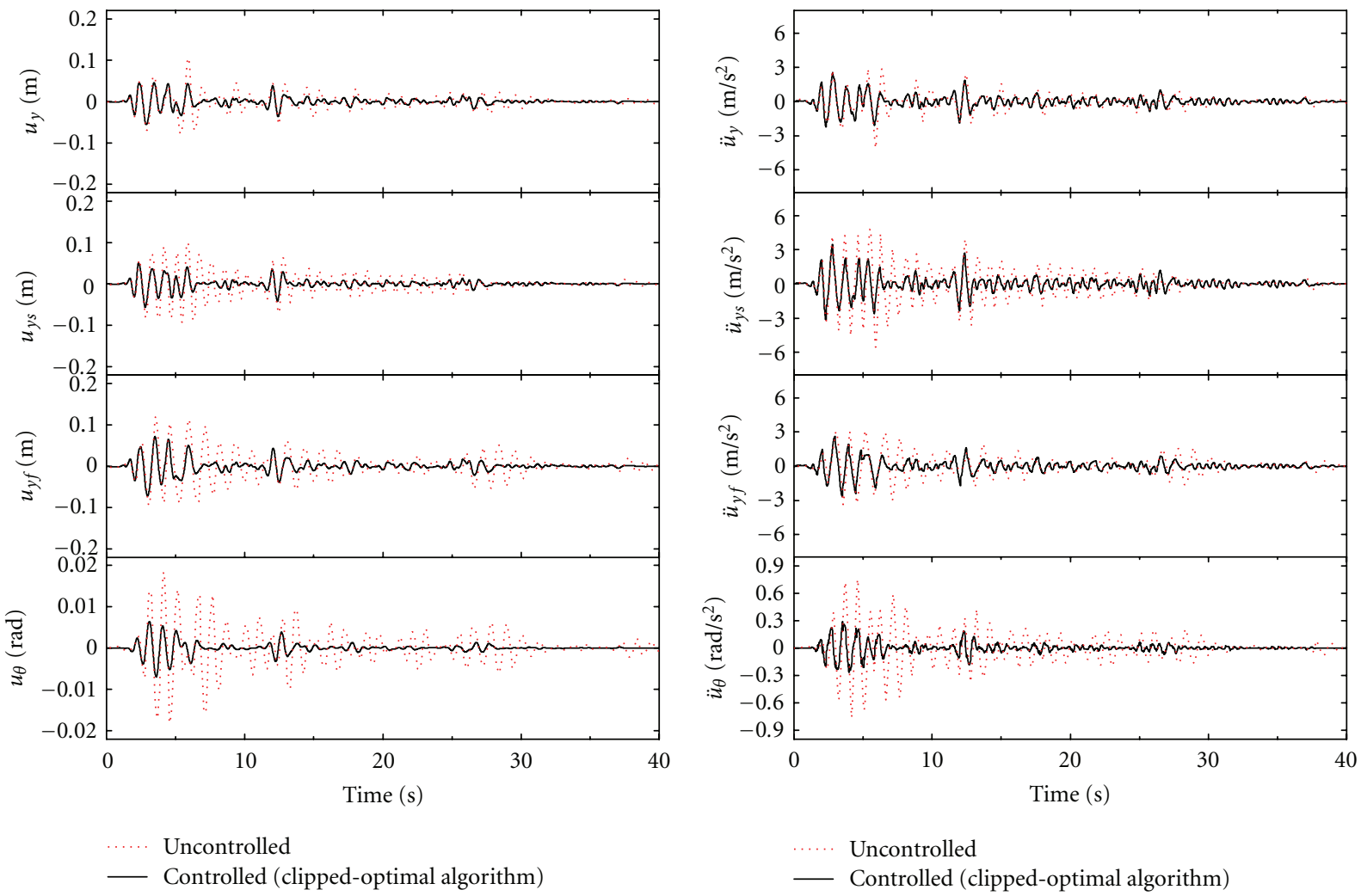

Figure 5: Time histories for various uncontrolled and controlled displacements and accelerations under Imperial Valley, 1940 earthquake $\left(T_{y}=1 \mathrm{~s}, \Omega_{\theta}=1, e_{x} / r=0.3\right)$.

the MR dampers are adequate to keep the response of the structure in the linear range. The equations of motion of the system in the matrix form are expressed as

$$
\mathbf{M u ̈}+\mathbf{C} \dot{\mathbf{u}}+\mathbf{K u}=-\mathbf{M \Gamma} \ddot{\mathbf{u}}_{\mathrm{g}}+\Lambda \mathbf{f},
$$

where $\mathbf{M}, \mathbf{C}$, and $\mathbf{K}$ are mass, damping, and stiffness matrices of the system, respectively; $\mathbf{u}=\left\{u_{y} u_{\theta}\right\}^{\mathrm{T}}$ is the displacement vector; $\Gamma$ is the influence coefficient vector; $\ddot{\mathbf{u}}_{\mathrm{g}}=\left\{\ddot{u}_{g y} 0\right\}^{\mathrm{T}}$ is the ground acceleration vector; $\ddot{u}_{g y}$ is the ground acceleration in $y$-direction, $\boldsymbol{\Lambda}$ is the matrix that defines the location of control devices, and $\mathbf{f}$ is the vector of control forces.

The mass matrix can be expressed as

$$
\mathbf{M}=\left[\begin{array}{cc}
m & 0 \\
0 & m r^{2}
\end{array}\right],
$$



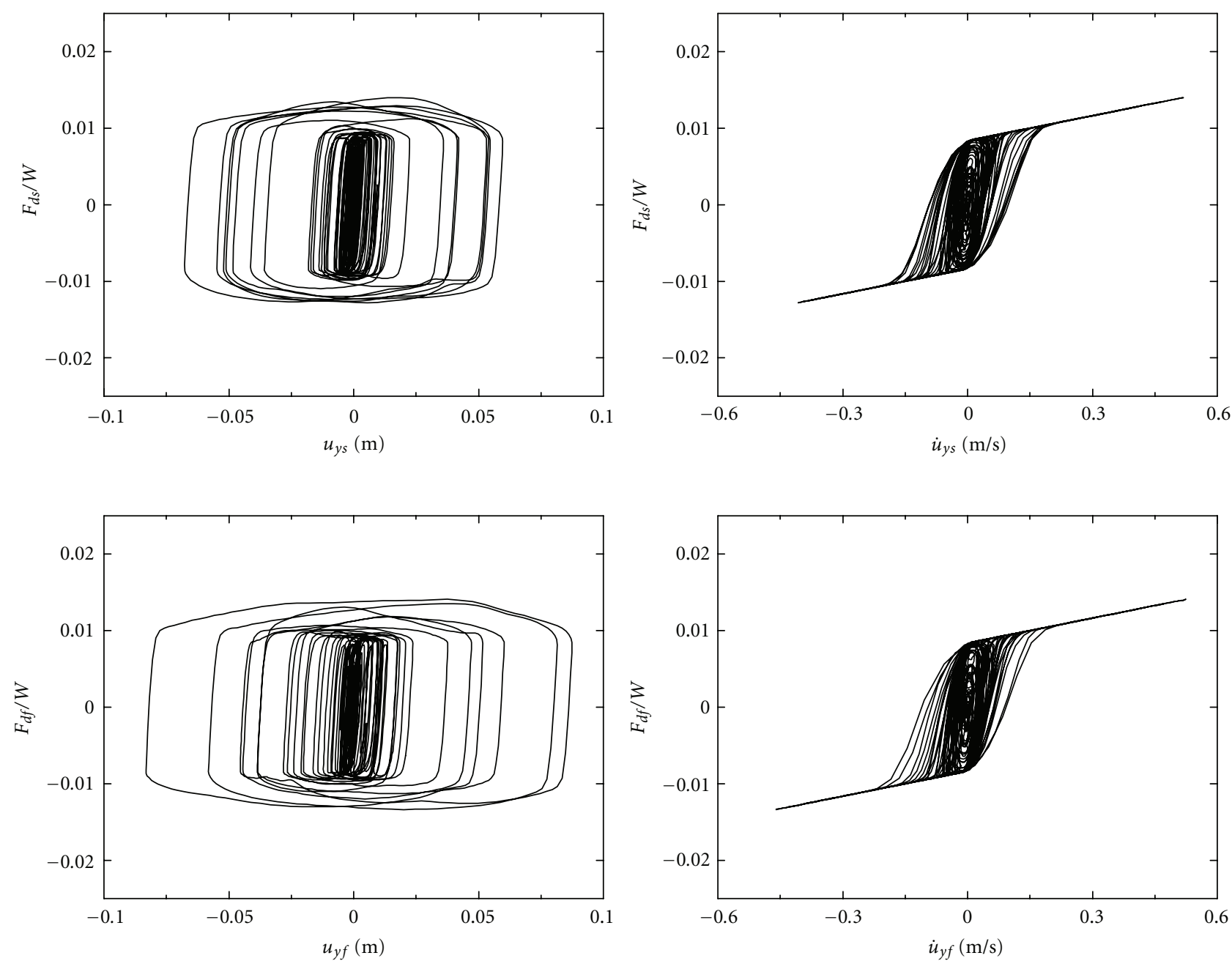

FIGURE 6: Normalized damper force-displacement and velocity loops for dampers located at stiff and flexible edges for passive-off algorithm under Imperial Valley, 1940 earthquake $\left(T_{y}=1 \mathrm{~s}, \Omega_{\theta}=1, e_{x} / r=0.3\right)$.

where $m$ represents the lumped mass of the deck; $r$ is the mass radius of gyration about the vertical axis through CM which is given by, $r=\sqrt{\left(a^{2}+b^{2}\right) / 12}$; where $a$ and $b$ are the plan dimensions of the building.

The stiffness matrix of the system is obtained as follows, after doing some algebraic manipulations [4]

$$
\begin{gathered}
\mathbf{K}=K_{y}\left[\begin{array}{cc}
1 & e_{x} \\
e_{x} & e_{x}^{2}+r^{2} \Omega_{\theta}^{2}
\end{array}\right], \\
e_{x}=\frac{1}{K_{y}} \sum_{i} K_{y i} x_{i}, \quad \Omega_{\theta}=\frac{\omega_{\theta}}{\omega_{y}}, \\
\omega_{\theta}=\sqrt{\frac{K_{\theta r}}{m r^{2}}}, \quad \omega_{y}=\sqrt{\frac{K_{y}}{m}}, \\
K_{\theta r}=K_{\theta \theta}-e_{x}^{2} K_{y}, \quad K_{\theta \theta}=\sum_{i} K_{x i} y_{i}^{2}+\sum_{i} K_{y i} x_{i}^{2},
\end{gathered}
$$

where $K_{y}$ denotes the total lateral stiffness of the building system in $y$-direction; $e_{x}$ is the structural eccentricity between $\mathrm{CM}$ and $\mathrm{CR}$ of the system; $\Omega_{\theta}$ is the ratio of uncoupled torsional to lateral frequency of the system; $K_{y i}$ indicates the lateral stiffness of $i$ th column in $y$-direction; $x_{i}$ is the $x$-coordinate distance of $i$ th element with respect to $\mathrm{CM} ; \omega_{y}$ is uncoupled lateral frequency of the system; $\omega_{\theta}$ is uncoupled torsional frequency of the system; $K_{\theta r}$ is torsional stiffness of the system about a vertical axis at the CR; $K_{\theta \theta}$ is torsional stiffness of the system about a vertical axis at the CM; $K_{x i}$ indicates the lateral stiffness of $i$ th column in $x$-direction; $y_{i}$ is the $y$-coordinate distance of $i$ th element with respect to CM.

The damping matrix of the system is not known explicitly and it is constructed from the Rayleigh's damping considering mass and stiffness proportional as

$$
\mathbf{C}=a_{0} \mathbf{M}+a_{1} \mathbf{K}
$$

in which $a_{0}$ and $a_{1}$ are the coefficients depends on damping ratio of two vibration modes. For the present study 5\% damping is considered for both modes of vibration of system.

The governing equations of motion are solved using the state space method $[16,17]$ and rewritten as

$$
\dot{\mathbf{z}}=\mathbf{A z}+\mathbf{B f}+\mathbf{E} \ddot{\mathbf{u}}_{\mathrm{g}},
$$



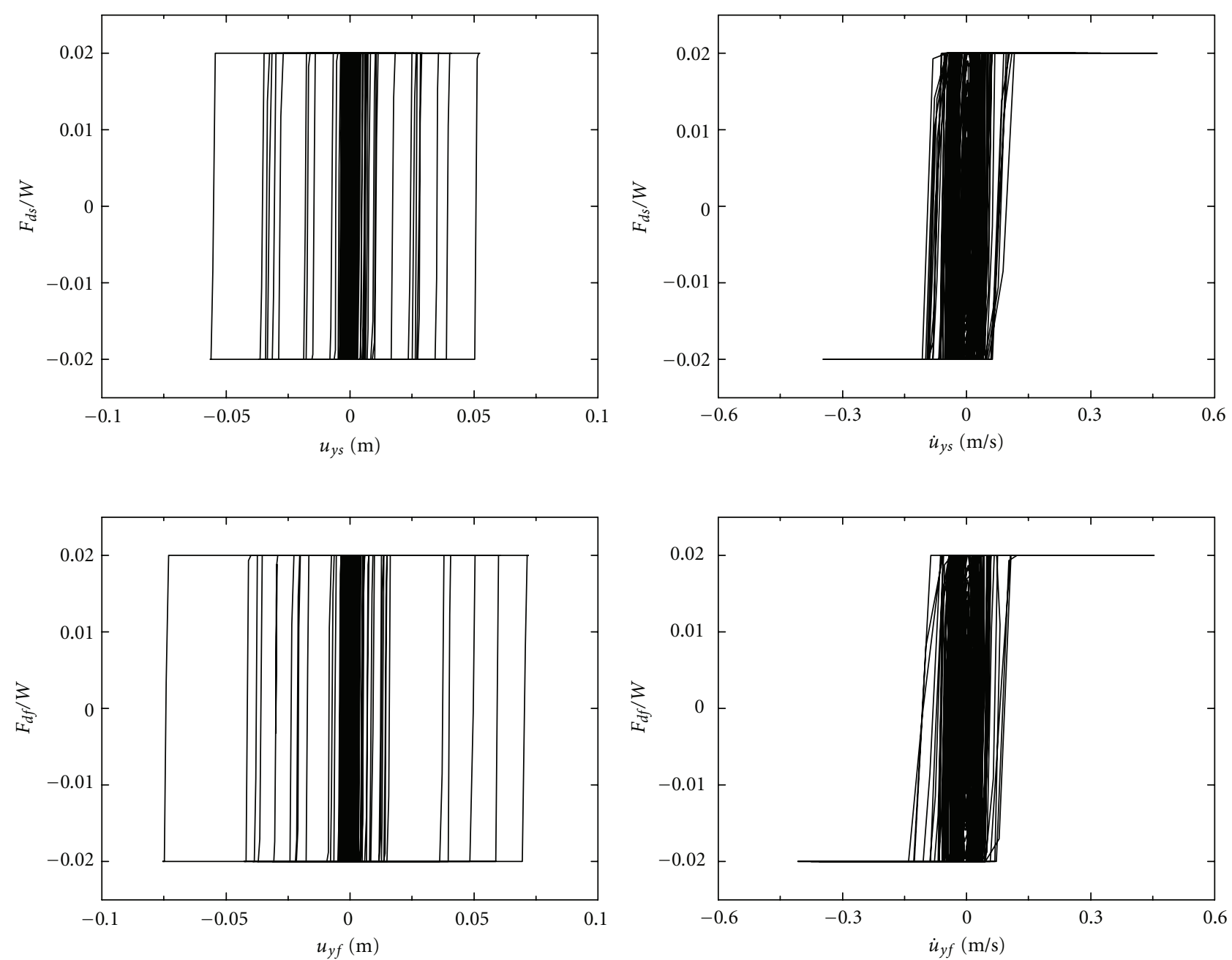

FIGURE 7: Normalized damper force-displacement and velocity loops for dampers located at stiff and flexible edges for passive-on algorithm under Imperial Valley, 1940 earthquake $\left(T_{y}=1 \mathrm{~s}, \Omega_{\theta}=1, e_{x} / r=0.3\right)$.

where $\mathbf{z}=\{\mathbf{u} \dot{\mathbf{u}}\}^{\mathrm{T}}$ is a state vector; $\mathbf{A}$ is the system matrix; $\mathbf{B}$ is the distribution matrix of control forces; $\mathrm{E}$ is the distribution matrix of excitations. These matrices are expressed as,

$$
\begin{gathered}
\mathbf{A}=\left[\begin{array}{cc}
\mathbf{0} & \mathbf{I} \\
-\mathbf{M}^{-1} \mathbf{K} & -\mathbf{M}^{-1} \mathbf{C}
\end{array}\right], \quad \mathbf{B}=\left[\begin{array}{c}
\mathbf{0} \\
\mathbf{M}^{-1} \boldsymbol{\Lambda}
\end{array}\right], \\
\mathbf{E}=-\left[\begin{array}{l}
\mathbf{0} \\
\Gamma
\end{array}\right],
\end{gathered}
$$

in which $\mathbf{I}$ is the identity matrix.

Equation (9) is discretized in time domain, and the excitation and control forces are assumed to be constant within any time interval, the solution may be written in an incremental form $[16,17]$

$$
\mathbf{z}[k+1]=\mathbf{A}_{\mathbf{d}} \mathbf{z}[k]+\mathbf{B}_{\mathbf{d}} \mathbf{f}[k]+\mathbf{E}_{\mathbf{d}} \ddot{\mathbf{u}}_{\mathbf{g}}[k],
$$

where $k$ denotes the time step; and $\mathbf{A}_{\mathbf{d}}=e^{\mathbf{A} \Delta t}$ represents the discrete-time system matrix with $\Delta t$ as the time interval. The constant coefficient matrices $\mathbf{B}_{\mathbf{d}}$ and $\mathbf{E}_{\mathbf{d}}$ are the discrete-time counterparts of the matrices $\mathbf{B}$ and $\mathbf{E}$ and can be written as

$$
\mathbf{B}_{\mathbf{d}}=\mathbf{A}^{-1}\left(\mathbf{A}_{\mathbf{d}}-\mathbf{I}\right) \mathbf{B}, \quad \mathbf{E}_{\mathbf{d}}=\mathbf{A}^{-1}\left(\mathbf{A}_{\mathbf{d}}-\mathbf{I}\right) \mathbf{E} .
$$

\section{Semiactive Clipped-Optimal Control Algorithm}

The clipped-optimal control algorithm based on acceleration feedback is used herein as shown in Figure 3(a). This algorithm has been found to be among the best performing of several non linear semiactive controllers for MR devices $[15,18]$.

The measurement equation is given by

$$
\mathbf{y}_{m}=\mathbf{C}_{m} \mathbf{z}+\mathbf{D}_{m} \mathbf{f}+\mathbf{v},
$$

where $\mathbf{y}_{m}$ is the vector of measured outputs, and $\mathbf{v}$ is the measurement noise vector. In this study the measurements considered for control force determination include the accelerations at flexible and stiff edge of the structure. 

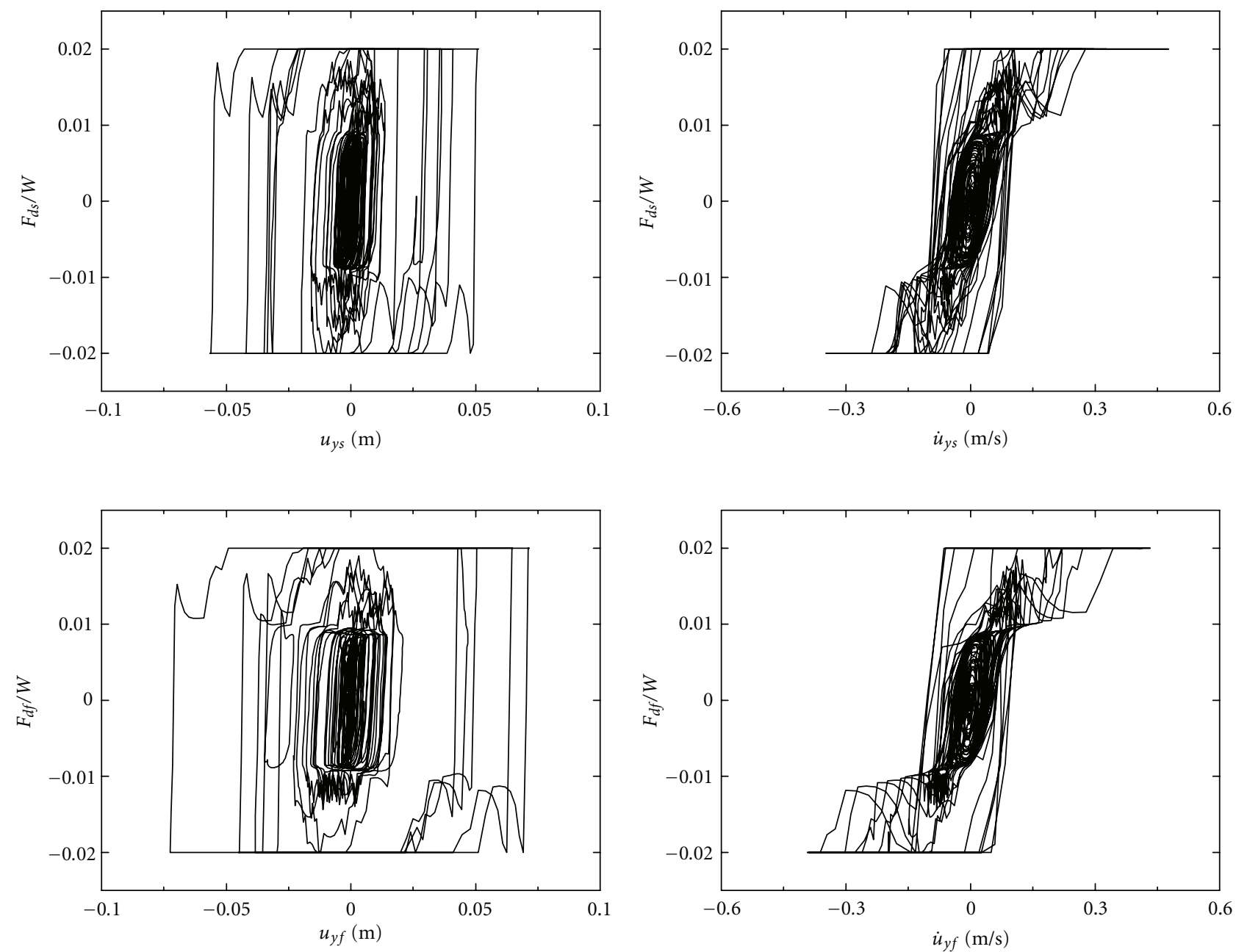

Figure 8: Normalized damper force-displacement and velocity loops for dampers located at stiff and flexible edges for semiactive clippedoptimal control algorithm under Imperial Valley, 1940 earthquake $\left(T_{y}=1 \mathrm{~s}, \Omega_{\theta}=1, e_{x} / r=0.3\right)$.
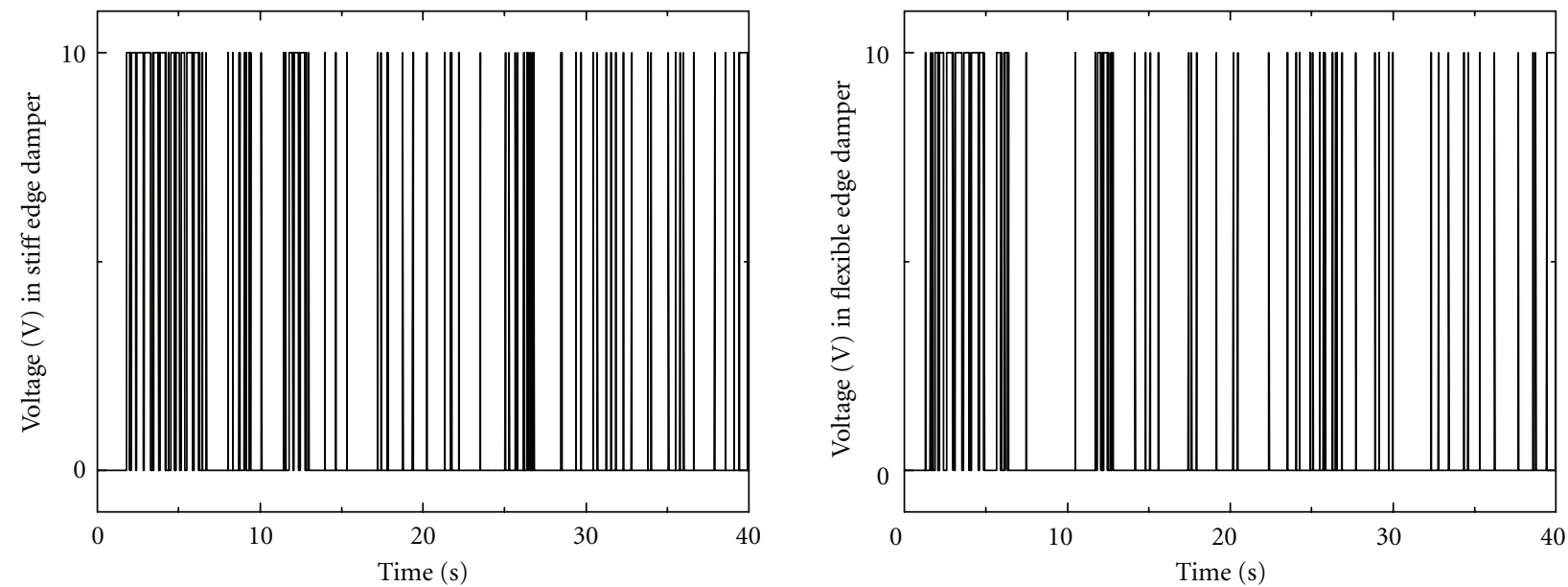

FIgURE 9: Time variation of applied voltage for dampers located at stiff and flexible edges for semiactive clipped-optimal control under Imperial Valley, 1940 earthquake $\left(T_{y}=1 \mathrm{~s}, \Omega_{\theta}=1, e_{x} / r=0.3\right)$. 

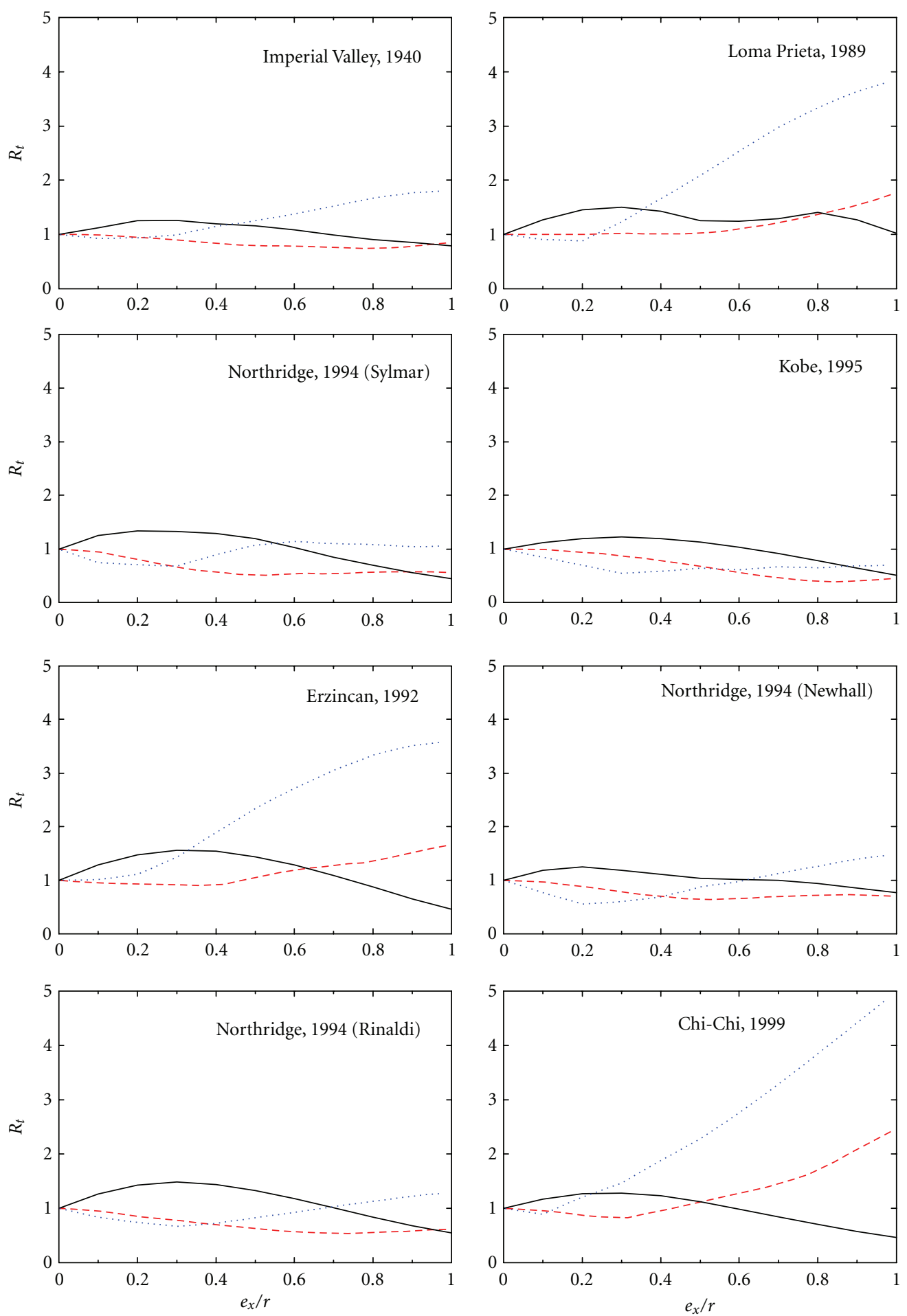

$$
\begin{array}{ll}
---u_{y} \\
-u_{y s}
\end{array}
$$$$
\begin{array}{ll}
-- & u_{y} \\
- & u_{y s} \\
\ldots \ldots & u_{y f}
\end{array}
$$

Figure 10: Effect of eccentricity on response ratio, $R_{t}$ for various peak displacements $\left(T_{y}=1 \mathrm{~s}, \Omega_{\theta}=0.5\right)$. 
The matrices used in the measurement equation have the following form:

$$
\begin{aligned}
& \mathbf{C}_{m}=\left[\begin{array}{lll}
-\mathbf{P}_{m} \mathbf{M}^{-1} \mathbf{K} & -\mathbf{P}_{m} \mathbf{M}^{-1} \mathbf{C}
\end{array}\right], \\
& \mathbf{D}_{m}=\left[\mathbf{P}_{m} \mathbf{M}^{-1} \Lambda\right], \quad \mathbf{P}_{m}=\left[\begin{array}{cc}
1 & l_{a 1} \\
1 & l_{a 2}
\end{array}\right],
\end{aligned}
$$

where $l_{a 1}$ and $l_{a 2}$ are the coordinates of the acceleration measurements of flexible and stiff edges, respectively. For the study carried out herein, the accelerometers are assumed to be fixed at the edges of building as shown in Figure 2(b).

The approach considered is to append a force feedback loop to induce the MR damper to produce approximately a desired control force $f_{c i}$. The force generated by the MR damper cannot be commanded; only the voltage $v_{i}$ applied to the current driver for the MR damper can be directly changed as follows. When the MR damper is providing the desired optimal control force (i.e., $f_{i}=f_{c i}$ ), the voltage applied to the damper should remain at the present level. If the magnitude of the force produced by the damper is smaller than the magnitude of the desired optimal control force and the two forces have the same sign, the voltage applied to the current driver increases to the maximum level so as to increase the force produced by the damper to match the desired control force. Otherwise, the commanded voltage is set to zero. The algorithm for selecting the command signal is graphically represented in Figure 3(a) and can be stated as $[15,18]$

$$
v_{i}=V_{\max } H\left\{\left(f_{c i}-f_{i}\right) f_{i}\right\},
$$

where $V_{\max }$ is the voltage sent to the current driver, associated with saturation of the magnetic field in MR damper, and $H(\cdot)$ is the Heaviside step function. In this study, $\mathrm{H}_{2} / \mathrm{LQG}$ (Linear Quadratic Gaussian) strategy is employed as a nominal controller to have desired control forces. Figure 3(b) represents the block diagram of the semiactive control system.

For the design of $\mathrm{H}_{2} / \mathrm{LQG}$ controller, the absolute acceleration of the ground, $\ddot{u}_{g y}$, is taken to be a stationary white noise, and an infinite horizon performance index is chosen as

$$
J=\lim _{\tau \rightarrow \infty} \frac{1}{\tau} E\left[\int_{0}^{\tau}\left\{\mathbf{y}_{m}^{\mathrm{T}} \mathbf{Q} \mathbf{y}_{m}+\mathbf{f}^{\mathrm{T}} \mathbf{R} \mathbf{f}\right\} \mathrm{dt}\right],
$$

where $\mathbf{Q}$ and $\mathbf{R}$ are weighting matrices for the vector of regulated/measured responses $\mathbf{y}_{m}=\left\{\ddot{u}_{m f} \ddot{u}_{m s}\right\}^{\mathrm{T}}$ and of control forces $\mathbf{f}=\left\{F_{d f} F_{d s}\right\}^{\mathrm{T}}$, respectively. Where, $\ddot{u}_{m f}$ and $\ddot{u}_{m s}$ are the flexible and stiff edge accelerations measured by the accelerometers which are placed at the respective edges on the floor, as shown in Figure 2(b). For design purposes, the measurement noise vector $\mathbf{v}$ is assumed to contain identically distributed, statistically independent Gaussian white noise processes, with $S_{\ddot{u}_{g y} \ddot{u}_{g y}} / S_{v_{i} v_{i}}=\gamma_{g}=50$.

The Nominal controller is represented as [10]

$$
\begin{gathered}
\dot{\hat{\mathbf{z}}}=\left(\mathbf{A}-\mathbf{L}_{g} \mathbf{C}_{m}\right) \hat{\mathbf{z}}+\mathbf{L}_{g} \mathbf{y}_{m}+\left(\mathbf{B}-\mathbf{L}_{g} \mathbf{D}_{m}\right) \mathbf{f}, \\
\mathbf{f}_{c}=-\mathbf{K}_{g} \hat{\mathbf{z}}
\end{gathered}
$$

where $\mathbf{L}_{g}$ is the gain matrix for the state estimator; $\hat{\mathbf{z}}$ is the estimated state vector; $\mathbf{K}_{g}$ is the gain matrix for the linear quadratic regulator obtained as follows:

$$
\mathbf{K}_{g}=\mathbf{B}^{\prime} \mathbf{R}^{-1} \mathbf{P},
$$

where $\mathbf{P}$ is the solution of the algebraic Ricatti equation given by

$$
\begin{gathered}
\mathbf{0}=\mathbf{P A}+\mathbf{A}^{\prime} \mathbf{P}-\mathbf{P B R}^{-1} \mathbf{B}^{\prime} \mathbf{P}+\mathbf{C}_{m}^{\prime} \mathbf{Q} \mathbf{C}_{m}, \\
\mathbf{L}_{g}=\left(\mathbf{C}_{m} \mathbf{S}\right)^{\prime},
\end{gathered}
$$

where $\mathbf{S}$ is the solution of the algebraic Ricatti equation given by

$$
\mathbf{0}=\mathbf{S A}^{\prime}+\mathbf{A S}-\mathbf{S C}_{m}^{\prime} \mathbf{C}_{m} \mathbf{S}+\gamma_{g} \mathbf{E E}^{\prime}
$$

The response weighting matrix $\mathbf{Q}$ corresponding to the regulated output vector $\mathbf{y}_{m}$ is considered as follows:

$$
\mathbf{Q}=q_{w} \cdot\left[\begin{array}{ll}
1 & 0 \\
0 & 1
\end{array}\right]
$$

where $\mathbf{q}_{w}$ is the coefficient for weighting matrix $\mathbf{Q}$.

The weighting matrix $\mathbf{R}$ which is corresponding to the control force vector is considered as follows:

$$
\mathbf{R}=\mathbf{r}_{w} \cdot\left[\begin{array}{ll}
1 & 0 \\
0 & 1
\end{array}\right]
$$

where $r_{w}$ is the coefficient for weighting matrix $\mathbf{R}$.

\section{Numerical Study}

The seismic response of linearly elastic, idealized singlestorey, one-way asymmetric system installed with semiactive MR dampers with clipped-optimal control algorithm is investigated by numerical simulation study. The response quantities of interest are lateral and torsional displacements of the floor mass obtained at the CM $\left(u_{y}\right.$ and $\left.u_{\theta}\right)$, displacements at stiff and flexible edges of the system $\left(u_{y s}\right.$ and $u_{y f}=$ $\left.u_{y} \pm b u_{\theta} / 2\right)$, lateral and torsional accelerations of the floor mass obtained at the CM ( $\ddot{u}_{y}$ and $\left.\ddot{u}_{\theta}\right)$, accelerations at stiff and flexible edges of the system $\left(\ddot{u}_{y s}\right.$ and $\left.\ddot{u}_{y f}=\ddot{u}_{y} \pm b \ddot{u}_{\theta} / 2\right)$, base shear $\left(V_{y}\right)$, as well as damper control forces at stiff edge $\left(F_{d s}\right)$ and at flexible edge $\left(F_{d f}\right)$ of the building. The response of the system is investigated under following parametric variations: structural eccentricity ratio $\left(e_{x} / r\right)$, uncoupled lateral time period of system $\left(T_{y}=2 \pi / \omega_{y}\right)$ and ratio of uncoupled torsional to lateral frequency of the system $\left(\Omega_{\theta}=\right.$ $\left.\omega_{\theta} / \omega_{y}\right)$. The peak responses are obtained corresponding to the important parameters which are listed above and variations are plotted for the eight considered earthquake ground motions namely, Imperial Valley (1940), Loma Prieta (1989), Northridge (Sylmar, 1994), Kobe (1995), Erzincan (1992), Northridge (Newhall, 1994), Northridge (Rinaldi, 1994), and Chi-Chi (1999) for the present study with corresponding peak ground acceleration (PGA) values of 
TABLE 1: Details of earthquake motions considered for the numerical study.

\begin{tabular}{|c|c|c|c|c|}
\hline Earthquake & Recording Station & Component & Duration $(\mathrm{sec})$ & PGA (g) \\
\hline Imperial Valley, 19th May, 1940 & El Centro (Array \# 9) & ELC 180 & 40 & 0.31 \\
\hline Loma Prieta, 18th October, 1989 & Los Gatos Presentation Center & LGP 000 & 25 & 0.96 \\
\hline Northridge, 17th January, 1994 & Sylmar Converter Station & SCS 142 & 40 & 0.89 \\
\hline Kobe, 16th January, 1995 & Japan Meteorological Agency & KJM 000 & 48 & 0.82 \\
\hline Erzincan, 13th March, 1992 & Erzincan & ERZ-NS & 20 & 0.51 \\
\hline Northridge, 17th January, 1994 & Newhall Fire Station & NWH360 & 40 & 0.59 \\
\hline Northridge, 17th January, 1994 & Rinaldi Receiving Station & RRS228 & 20 & 0.82 \\
\hline Chi-Chi, 20th September, 1999 & TCU068 & TCU068-N & 90 & 0.57 \\
\hline
\end{tabular}

TABle 2: Parameters for the MR damper model (200 kN capacity) [19].

\begin{tabular}{lccc}
\hline Parameter & Value & Parameter & Value \\
\hline$\alpha_{a}$ & $46.2 \mathrm{kN} / \mathrm{m}$ & $k_{1}$ & $0.0097 \mathrm{kN} / \mathrm{m}$ \\
$\alpha_{b}$ & $41.2 \mathrm{kN} / \mathrm{m} / \mathrm{V}$ & $\gamma_{m}$ & $164.0 \mathrm{~m}^{-2}$ \\
$c_{0 a}$ & $110.0 \mathrm{kN} \mathrm{s} / \mathrm{m}$ & $\beta_{m}$ & $164.0 \mathrm{~m}^{-2}$ \\
$c_{0 b}$ & $114.3 \mathrm{kN} \mathrm{s} / \mathrm{m} / \mathrm{V}$ & $A_{m}$ & 1107.2 \\
$c_{1 a}$ & $8359.2 \mathrm{kN} \mathrm{s} / \mathrm{m}$ & $n$ & 2 \\
$c_{1 b}$ & $7482.9 \mathrm{kN} \mathrm{s} / \mathrm{m} / \mathrm{V}$ & $\eta$ & $100 \mathrm{~s}^{-1}$ \\
$k_{0}$ & $0.002 \mathrm{kN} / \mathrm{m}$ & $x_{0}$ & $0.18 \mathrm{~m}^{2}$ \\
\hline
\end{tabular}

$0.31 \mathrm{~g}, 0.96 \mathrm{~g}, 0.89 \mathrm{~g}, 0.82 \mathrm{~g}, 0.51 \mathrm{~g}, 0.59 \mathrm{~g}, 0.82 \mathrm{~g}$, and $0.57 \mathrm{~g}$ as per the details summarized in Table 1. The input parameters considered for the present study are; Total weight of building, $W=10,000 \mathrm{kN}$ and aspect ratio of plan dimension is kept as unity. For the numerical simulation study carried out herein, two MR dampers, each having $200 \mathrm{kN}$ capacity [20] are assumed to be installed at the edges of the building as shown in Figure 2. The parameters of mechanical model of a damper are presented in Table 2 [19].

In order to study the effectiveness of implemented semiactive control system, the response is expressed in terms of indices, $R_{e}$ and $R_{t}$ are defined as follows:

$$
\begin{aligned}
R_{e} & =\frac{\text { Peak (or RMS) response of controlled asymmetric system }}{\text { Peak (or RMS) response of corresponding uncontrolled system }}, \\
R_{t} & =\frac{\text { Peak (or RMS) response of controlled asymmetric system }}{\text { Peak (or RMS) response of corresponding symmetric system }} .
\end{aligned}
$$

The value of $R_{e}$ less than one indicates that the implemented semiactive control system is effective in controlling the responses. On the other hand, the value of $R_{t}$ reflects the effects of torsional coupling on the effectiveness of semiactive control system and seismic behavior of system. The value of $R_{t}$ greater than one indicates that the response of controlled asymmetric system increases due to torsional coupling as compared to the corresponding symmetric system. The effects of various levels of excitations for particular earthquake motion are not studied by considering the fact that the main objective is to investigate the effects of torsional coupling on the effectiveness of semiactive device for asymmetric systems as compared to symmetric systems and the responses are obtained in terms of response ratios. Moreover, in past, some work have been reported with the use of semiactive MR damper with the assumption that the building behaves in linear range and also without considering the effects of different levels of excitations $[15,18,21]$.

In order to determine the optimum coefficients of weighting matrices $\mathbf{Q}$ and $\mathbf{R}$, the response ratio, $R_{e}$ for peak and root mean square (RMS) values of displacements as well as accelerations of the floor mass are obtained for the symmetric system with $T_{y}=1 \mathrm{~s}$. Initially, the coefficient, $r_{w}$ of the matrix, $\mathbf{R}$ is considered as unity and the coefficient, $q_{w}$ of matrix, $\mathbf{Q}$ is varied by placing higher weightage on the response quantities. The response are obtained under Imperial Valley, 1940 earthquake and shown in Figure 4(a). From the figure, it can be noticed that initially with the increase in $q_{w}$, the ratio, $R_{e}$ decreases up to certain limit and then increases with further increase in value of $q_{w}$. This means there exists an optimum value of coefficient, $q_{w}$ for which $R_{e}$ is minimum, which shows the maximum reduction in various responses. Thus, the optimum value for 

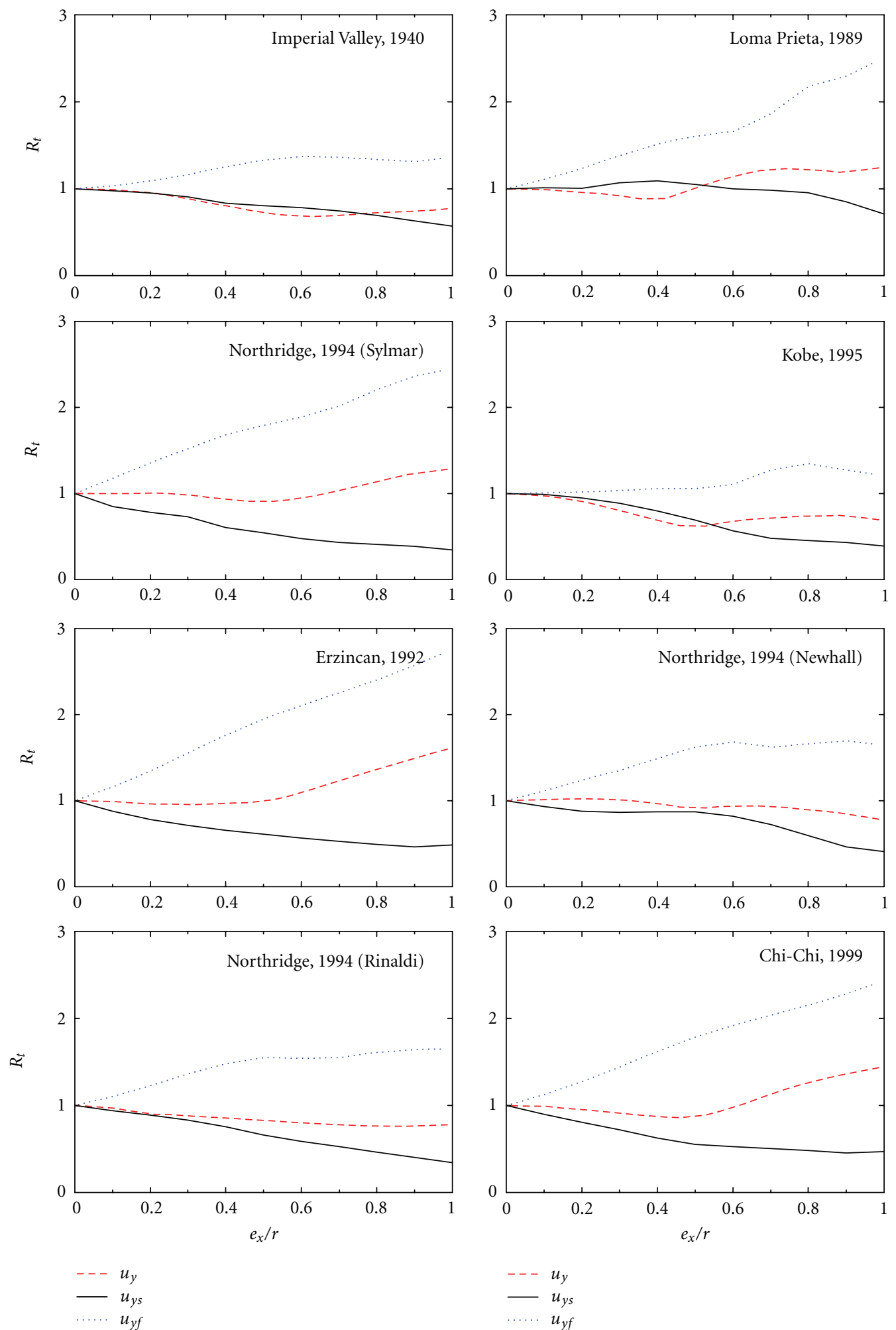

$$
\begin{array}{ll}
--- & u_{y} \\
- & u_{y s} \\
\ldots \ldots & u_{y f}
\end{array}
$$

FIGURE 11: Effect of eccentricity on response ratio, $R_{t}$ for various peak displacements $\left(T_{y}=1 \mathrm{~s}, \Omega_{\theta}=1\right)$.

$q_{w}$ is found to be $10^{11}$. Further, trials have been done by keeping $q_{w}$ as constant (i.e., $q_{w}=10^{11}$ ) and by varying the coefficient, $r_{w}$ and the results are shown in Figure 4(b). From the figure, it can be noticed that the ratio, $R_{e}$ is minimum corresponding to the value of $r_{w}=1$. Moreover, the above results are also verified for the systems with different time period, $T_{y}$ (i.e., varied from $0.1 \mathrm{~s}$ to $3 \mathrm{~s}$ ), and it is found that the optimum values of $q_{w}$ and $r_{w}$ remains almost in the similar range such as to have optimum compromise between the reduction in peak and RMS displacement 
and acceleration responses. Thus, for the study carried out herein, the optimum coefficients for the weighting matrices $\mathbf{Q}$ and $\mathbf{R}$ are considered as $q_{w}=10^{11}$ and $r_{w}=1$.

The present study is carried out by considering two MR dampers (one on each side of building), each of $200 \mathrm{kN}$ capacity with semiactive clipped-optimal control algorithm with maximum applied voltage of $10 \mathrm{~V}$. The responses are also obtained with passive-off and passive-on cases, with constant zero voltage and with constant maximum voltage, respectively, and compared with the semiactive control case. However, the main focus is to study the behavior of the system equipped with semiactive dampers. Figure 5 shows the time histories of various displacement and acceleration response quantities of the uncontrolled building compared with the corresponding building controlled with semiactive MR dampers with clipped-optimal control algorithm.

The responses are obtained for the system with $T_{y}=1 \mathrm{~s}$, $\Omega_{\theta}=1$, and $e_{x} / r=0.3$ (intermediate eccentricity) under Imperial Valley, 1940 earthquake. The significant reduction in displacement and acceleration responses at $\mathrm{CM}$, at flexible and stiff edges as well as torsional response can be noticed from the figure. Thus, the semiactive system is quite effective in reducing lateral-torsional responses.

Furthermore, Table 3 depicts the comparison between the three control strategies, namely, passive-off, passive-on, and semiactive clipped-optimal control for the system with $T_{y}=1 \mathrm{~s}, \Omega_{\theta}=1, e_{x} / r=0.3$ under Imperial Valley, 1940 earthquake. The ratio, $R_{e}$ for various responses based on peak and RMS values are summarized herein. In general, ratio $R_{e}$ comes out be less than unity for all control strategies implying the effectiveness of control systems. It is further observed that passive-on strategy gives higher reduction in peak and RMS displacements and accelerations as compared to passive-off case. Also, it is observed that the reduction in peak displacements and accelerations obtained at CM $\left(u_{y}\right.$ and $\left.\ddot{u}_{y}\right)$, at edges $\left(u_{y s}, u_{y f}, \ddot{u}_{y s}\right.$, and $\left.\ddot{u}_{y f}\right)$ as well as its torsional components $\left(u_{\theta}\right.$ and $\left.\ddot{u}_{\theta}\right)$ for the semiactive case is found as little higher or comparable with those obtained with passive-on case. Moreover, the reduction in RMS of various displacement quantities is slightly higher for passiveon case as compared to corresponding semiactive case, whereas higher reduction in RMS of various acceleration quantities is found for semiactive case as compared to passive-on case. The table also shows the normalized control forces of dampers which are placed at the edges of the building. It is important to note that the RMS control forces required for passive-on case is much more higher than the passive-off case while for the semiactive case it is only little higher than passive-off case. This reflects that, for the semiactive clipped-optimal control algorithm, with little increase in RMS damper forces as compared to passive-off case, the higher or comparable reduction in peak and RMS values of lateral, edge, and torsional responses is obtained than those which is obtained by passive-on case.

Moreover, Figures 6, 7, and 8 represents the hysteresis loops for normalized damper force with displacement and velocity for the considered control strategies, namely, passive-off, passive-on, and semiactive clipped-optimal control case, respectively, for the system with $T_{y}=1 \mathrm{~s}, \Omega_{\theta}=1$, $e_{x} / r=0.3$ under Imperial Valley, 1940 earthquake. Further, Figure 9 shows the time variation of applied voltage for the semiactive clipped-optimal control case for the dampers located at stiff and flexible edges.

One of the key parameters affecting the lateral-torsional response of buildings is the structural eccentricity. In order to study the effects of eccentricity and torsional coupling on the seismic response of asymmetric systems, the variations of ratio, $R_{t}$ for lateral and edge displacements are plotted against eccentricity ratio, $e_{x} / r$ (which is varied from 0 to 1 ) for eight selected earthquakes. The variations are shown for torsionally flexible $\left(\Omega_{\theta}=0.5\right)$, strongly coupled $\left(\Omega_{\theta}=1\right)$ and torsionally stiff $\left(\Omega_{\theta}=2\right)$ systems with $T_{y}=1 \mathrm{~s}$ in Figures 10,11, and 12, respectively. It is observed that for the systems with $\Omega_{\theta}=0.5$, with increase in $e_{x} / r$, the ratio, $R_{t}$ for lateral displacement, $u_{y}$ decreases and remains less than unity, in general, whereas, the ratio, $R_{t}$ for $u_{y s}$ increases first, up to an intermediate eccentricity (i.e., $e_{x} / r<0.5$ ) and then decreases with further increase in eccentricity ratio. For flexible edge displacement, $u_{y f}$, the ratio, $R_{t}$ first decreases up to an intermediate eccentricity and then increases for higher eccentricity. This shows that for torsionally flexible system with an intermediate eccentricity, $u_{y}$ and $u_{y f}$ reduces and $u_{y s}$ increases due to torsional coupling as compared to corresponding symmetric system and for the system with higher eccentricity, $u_{y f}$ increases, and $u_{y}$ and $u_{y s}$ decrease due to torsional coupling except for Erzincan (1992) and Chi-Chi (1999) earthquakes. Hence, for torsionally flexible systems with an intermediate eccentricity, the effectiveness of control system is more for asymmetric system for reducing $u_{y}$ and $u_{y f}$ as compared to corresponding symmetric systems and hence it will be underestimated by ignoring the eccentricity and modeling the building as $2 \mathrm{D}$. Whereas, the effectiveness of control system is less for asymmetric system for reducing $u_{y s}$ as compared to corresponding symmetric systems and hence it will be overestimated for $u_{y s}$. Whereas, for torsionally flexible systems with higher eccentricities, effectiveness of control system will be underestimated for reducing $u_{y}$ and $u_{y s}$ and it will be overestimated for $u_{y f}$.

Moreover, as shown in Figures 11 and 12 for the systems with $\Omega_{\theta}=1$ and 2, the ratio, $R_{t}$ for $u_{y s}$ decreases and for response, $u_{y f}$, it increases with increase in eccentricity ratio. This implies that the effectiveness of control system is more for asymmetric system as compared to corresponding symmetric system in reducing $u_{y s}$ and hence it will be underestimated and the effectiveness is less for asymmetric system in reducing $u_{y f}$ and hence it will be underestimated by ignoring the effect of torsional coupling. Also, for the systems with $\Omega_{\theta}=1$, the ratio, $R_{t}$ for $u_{y}$ remains less that unity except for the systems with higher eccentricities. However, for torsionally stiff systems, the ratio, $R_{t}$ for lateral and edge displacements, remains very less sensitive to the variation of $e_{x} / r$. Thus, the effects of torsional coupling can be ignored for such systems while estimating the effectiveness of semiactive control system for asymmetric system as compared to symmetric system. Further, the difference between edge displacements of asymmetric and 
TABLE 3: Response ratio, $R_{e}$ for Peak and RMS Responses for various control strategies under Imperial Valley, 1940 earthquake $\left(T_{y}=1\right.$, $\left.\Omega_{\theta}=1, e_{x} / r=0.3\right)$.

\begin{tabular}{|c|c|c|c|c|}
\hline Response quantities & Control strategy & Passive-off & Passive-on & Semiactive clipped-optimal control \\
\hline \multirow{20}{*}{ Based on peak response } & \multirow{2}{*}{$R_{e}$ for $u_{y}$} & \multirow{2}{*}{0.56903} & 0.52736 & 0.51507 \\
\hline & & & $(7.32 \%)$ & $(9.48 \%)$ \\
\hline & \multirow{2}{*}{$R_{e}$ for $u_{y s}$} & \multirow{2}{*}{0.65228} & 0.54286 & 0.54447 \\
\hline & & & $(16.77 \%)$ & $(16.53 \%)$ \\
\hline & \multirow{2}{*}{$R_{e}$ for $u_{y f}$} & \multirow{2}{*}{0.71709} & 0.61866 & 0.59502 \\
\hline & & & $(13.73 \%)$ & $(17.02 \%)$ \\
\hline & \multirow{2}{*}{$R_{e}$ for $u_{\theta}$} & \multirow{2}{*}{0.56500} & 0.36206 & 0.36790 \\
\hline & & & $(35.92 \%)$ & $(35.89 \%)$ \\
\hline & \multirow{2}{*}{$R_{e}$ for $\ddot{u}_{y}$} & \multirow{2}{*}{0.61011} & 0.61266 & 0.60387 \\
\hline & & & $(-0.42 \%)$ & $(1.02 \%)$ \\
\hline & \multirow{2}{*}{$R_{e}$ for $\ddot{u}_{y s}$} & \multirow{2}{*}{0.67720} & 0.61226 & 0.61318 \\
\hline & & & $(9.59 \%)$ & $(9.45 \%)$ \\
\hline & \multirow{2}{*}{$R_{e}$ for $\ddot{u}_{y f}$} & \multirow{2}{*}{0.76390} & 0.72524 & 0.71258 \\
\hline & & & $(5.06 \%)$ & $(6.72 \%)$ \\
\hline & \multirow{2}{*}{$R_{e}$ for $\ddot{u}_{\theta}$} & \multirow{2}{*}{0.53690} & 0.36741 & 0.36840 \\
\hline & & & $(31.57 \%)$ & $(31.38 \%)$ \\
\hline & \multirow{2}{*}{$F_{d s} / W$} & \multirow{2}{*}{0.01401} & 0.02000 & 0.02000 \\
\hline & & & $(-42.80 \%)$ & $(-42.80 \%)$ \\
\hline & \multirow{2}{*}{$F_{d f} / W$} & \multirow{2}{*}{0.01407} & 0.02000 & 0.02000 \\
\hline & & & $(-42.11 \%)$ & $(-42.11 \%)$ \\
\hline \multirow{20}{*}{ Based on RMS response } & \multirow{2}{*}{$R_{e}$ for $u_{y}$} & \multirow{2}{*}{0.61004} & 0.49222 & 0.52683 \\
\hline & & & $(19.31 \%)$ & $(13.64 \%)$ \\
\hline & \multirow{2}{*}{$R_{e}$ for $u_{y s}$} & \multirow{2}{*}{0.52862} & 0.36608 & 0.38857 \\
\hline & & & $(30.75 \%)$ & $(26.49 \%)$ \\
\hline & $R$ for $u$ & 0.50951 & 0.38461 & 0.41568 \\
\hline & Ne tor a dyf & & $(24.51 \%)$ & $(19.17 \%)$ \\
\hline & $R$ for $u_{\theta}$ & 042665 & 0.24874 & 0.26326 \\
\hline & $\Lambda_{e} 101 u_{\theta}$ & 0.42603 & $(41.70 \%)$ & $(38.30 \%)$ \\
\hline & $R$ for $\ddot{u}$ & 068025 & 0.67366 & 0.63343 \\
\hline & $\kappa_{e} 101 u_{y}$ & & $(0.97 \%)$ & $(6.88 \%)$ \\
\hline & $R$ for $\ddot{u}$ & 055606 & 0.46018 & 0.44690 \\
\hline & $N_{e} 1010$ & & $(17.24 \%)$ & $(19.63 \%)$ \\
\hline & $R$ for $\ddot{u}$ & 055171 & 0.53870 & 0.49283 \\
\hline & $N_{e}+101-u_{y f}$ & & $(2.36 \%)$ & $(10.67 \%)$ \\
\hline & $R_{e}$ for $\ddot{u}_{\theta}$ & 0.44723 & 0.29753 & 0.29076 \\
\hline & $\Lambda_{e} 1014 \theta$ & $0.44 / 25$ & $(33.47 \%)$ & $(34.99 \%)$ \\
\hline & $F_{3} / W$ & 000718 & 0.01619 & 0.00969 \\
\hline & $\Gamma_{d s} / v v$ & & $(-125.49 \%)$ & $(-34.88 \%)$ \\
\hline & $F_{d f} / W$ & 000734 & 0.01627 & 0.00922 \\
\hline & $I_{d f} / v_{r}$ & & $(-121.68 \%)$ & $(-25.63 \%)$ \\
\hline
\end{tabular}

(Numbers in parentheses indicate percentage reduction as compared to the passive-off case. Positive numbers correspond to a response reduction.)

corresponding symmetric system is higher for strongly coupled and torsionally flexible systems as compared to torsionally stiff systems and the difference increases with the increase in structural eccentricity. Thus, for torsionally flexible and strongly coupled systems, the effects of torsional coupling can not be neglected while estimating the effectiveness of semiactive control system for asymmetric systems as compared to corresponding symmetric systems in controlling edge displacements.
To study the effects of torsional coupling on base shear, $V_{y}$, the variations of ratio, $R_{t}$ for $V_{y}$ are plotted against $e_{x} / r$ for three values of frequency ratios (i.e., $\Omega_{\theta}=0.5,1$ and 2) as shown in the Figure 13. From the figure, it can be observed that with increase in $e_{x} / r$, ratio, $R_{t}$ decreases, in general. Further, it is noticed that the ratio, $R_{t}$ for $V_{y}$, is more sensitive to variation of $e_{x} / r$ for systems with $\Omega_{\theta}=1$ followed by the systems with $\Omega_{\theta}=0.5$ and $\Omega_{\theta}=2$. This indicates that the torsional coupling reduces the base shear for controlled 
asymmetric systems as compared to corresponding symmetric systems and hence, the effectiveness of semiactive control system in reducing base shear is more for asymmetric systems as compared to corresponding symmetric systems and the effectiveness will be underestimated, if torsional coupling is ignored and building is modeled as 2D. This effect is more pronounced for the systems with higher superstructure eccentricities. Thus, the difference between the base shear of asymmetric and corresponding symmetric system increases with the increase in eccentricity ratio and it is significant for strongly coupled systems followed by torsionally flexible and torsionally stiff systems.

Moreover, the variations of ratio, $R_{t}$ for lateral and edge accelerations are shown for the systems with $\Omega_{\theta}=0.5,1$, and 2 in Figures 14, 15, and 16, respectively. In general, it is found that the trends for edge accelerations are opposite to those obtained for the edge displacements. It is further observed that for the systems with $\Omega_{\theta}=0.5$, with increase in $e_{x} / r$, the ratio, $R_{t}$ for lateral acceleration, $\ddot{u}_{y}$ and flexible edge acceleration, $\ddot{u}_{y f}$ decreases and that of stiff edge acceleration, $\ddot{u}_{y s}$ increases and remains more than a unity. Thus, for torsionally flexible systems, by ignoring the eccentricity, the effectiveness of semiactive control system will be underestimated for reducing $\ddot{u}_{y}$ and $\ddot{u}_{y f}$ and overestimated for $\ddot{u}_{y s}$. Similarly, for the system with $\Omega_{\theta}=1$, the ratio, $R_{t}$ for $\ddot{u}_{y}$ reduces with the increase in $e_{x} / r$ and for $\ddot{u}_{y s}$, the ratio remains slightly more that unity, in general. Whereas, for $\ddot{u}_{y f}$, the ratio remains less than or close to unity. However, the variation of $R_{t}$ for $\ddot{u}_{y f}$ remains less sensitive to $e_{x} / r$ as compared to those of responses, $\ddot{u}_{y}$ and $\ddot{u}_{y s}$. Also, it is found that the variation of $R_{t}$ with $e_{x} / r$ for edge accelerations are more pronounced for systems with $\Omega_{\theta}=0.5$ as compared to $\Omega_{\theta}=1$. Moreover, as shown in Figure 16, for systems with $\Omega_{\theta}=2$, with increase in $e_{x} / r$, the ratio, $R_{t}$ for $\ddot{u}_{y}$ and $\ddot{u}_{y s}$ slightly decreases and for $\ddot{u}_{y f}$, it increases slightly. However, the rate of change of ratio, $R_{t}$ with $e_{x} / r$ is very less sensitive for such systems as compared to systems with $\Omega_{\theta}=0.5$ and 1 . Thus, the effects of torsional coupling are more pronounced for torsionally flexible systems than strongly coupled systems while estimating the effectiveness of semiactive control system for asymmetric systems in controlling lateral and edge accelerations as compared to corresponding symmetric systems.

Figures 17 and 18 show the variations of response ratio, $R_{t}$ against $e_{x} / r$ for three values of $\Omega_{\theta}$, for normalized RMS control forces developed by the dampers which are installed at stiff edge $\left(F_{d s}\right)$ and at flexible edge $\left(F_{d f}\right)$ of the building. It can be observed that for torsionally flexible systems, the ratio, $R_{t}$ for $F_{d s}$ increases with increase in $e_{x} / r$ and remains more than unity and for $F_{d f}$, it decreases and remains less than unity except for the systems with higher eccentricities under Erzincan (1992) and Chi-Chi (1999) earthquakes. Hence, by ignoring the effects of torsional coupling for torsionally flexible systems, control forces at stiff edge, $F_{d s}$, will be underestimated, and at flexible edge, $F_{d f}$, it will be overestimated as compared to corresponding symmetric systems. Further, for strongly coupled systems, the ratio, $R_{t}$ for $F_{d s}$ decreases with the increase in $e_{x} / r$ and remains less than or very close to unity, whereas for $F_{d f}$, it increases with the increase $e_{x} / r$ and remains more than or close to unity. This implies that for strongly coupled systems, by ignoring the effects of torsional coupling, the control forces at stiff edge will be overestimated and at flexible edge, those will be underestimated as compared to corresponding symmetric systems. Whereas, for torsionally stiff systems, the ratio, $R_{t}$ for $F_{d s}$ decreases with the increase in $e_{x} / r$ and for $F_{d f}$, it increases with the increase $e_{x} / r$. Thus, by ignoring the effects of torsional coupling, control forces at stiff edge will be overestimated and at flexible edge, those will be underestimated as compared to corresponding symmetric systems. However, the rate of change for ratio, $R_{t}$ against $e_{x} / r$ for control forces is more sensitive for systems with $\Omega_{\theta}=0.5$ followed by the systems with $\Omega_{\theta}=1$ and 2 . Thus, the effects of torsional coupling on the estimation of control forces significantly depend on superstructure eccentricity and torsional to lateral frequency ratio.

To study, the effects of torsional coupling on the seismic behavior of laterally stiff and laterally flexible structural systems, the variations of ratio, $R_{t}$ for edge displacements and accelerations as well as for normalized RMS control forces are plotted against uncoupled lateral time period, $T_{y}$ (i.e., varied from $0.1 \mathrm{~s}$ to $3 \mathrm{~s}$ ). The results are obtained for an intermediate eccentricity ratio $\left(e_{x} / r=0.3\right)$ and shown in Figure 19 for the systems with $\Omega_{\theta}=0.5,1$ and 2 . The response ratios are obtained for eight selected earthquakes and the average trend from those earthquakes are shown in Figure 19. It can be noticed from the figure that for laterally stiff systems with $\Omega_{\theta}=0.5$ and 1 , the difference between the edge displacements of asymmetric and corresponding symmetric systems is higher as compared to laterally flexible systems and as the flexibility of superstructure increases the difference tends to decreases. Whereas, for torsionally stiff systems, variation in ratio $R_{t}$ for edge displacement and acceleration response remains insensitive to the change in values of $T_{y}$. Further, for laterally stiff systems with $\Omega_{\theta}=$ 0.5 , the difference between the flexible edge displacement of asymmetric and corresponding symmetric systems is significantly higher as compared to laterally flexible systems. This means that for laterally stiff systems, the torsional coupling significantly increases the flexible edge displacement for asymmetric system as compared to symmetric system. In addition, for laterally stiff systems with $\Omega_{\theta}=0.5$, the values of ratio, $R_{t}$ for $F_{d s}$ and $F_{d f}$ remains more than unity and for laterally flexible systems with $\Omega_{\theta}=0.5$, the ratio, $R_{t}$ for $F_{d s}$ remains more than unity and for $F_{d f}$, it remains less than unity. Thus, by ignoring the effects of torsional couplings for laterally stiff systems with $\Omega_{\theta}=0.5$, the control forces at stiff edge and flexible edge damper will be underestimated for asymmetric systems as compared to corresponding symmetric systems. Whereas, for laterally flexible systems with $\Omega_{\theta}=0.5$, the control forces at stiff edge damper will be underestimated and at flexible edge damper, it will be overestimated. Similarly, for laterally stiff systems with $\Omega_{\theta}=1$, the values of ratio, $R_{t}$ for $F_{d s}$ remains more than unity and for $F_{d f}$, it remains more than unity and for laterally flexible systems with $\Omega_{\theta}=1$, the ratio, $R_{t}$ for $F_{d s}$ and $F_{d f}$ remains close to the unity. Thus, by ignoring the effects of torsional couplings for laterally stiff systems with 

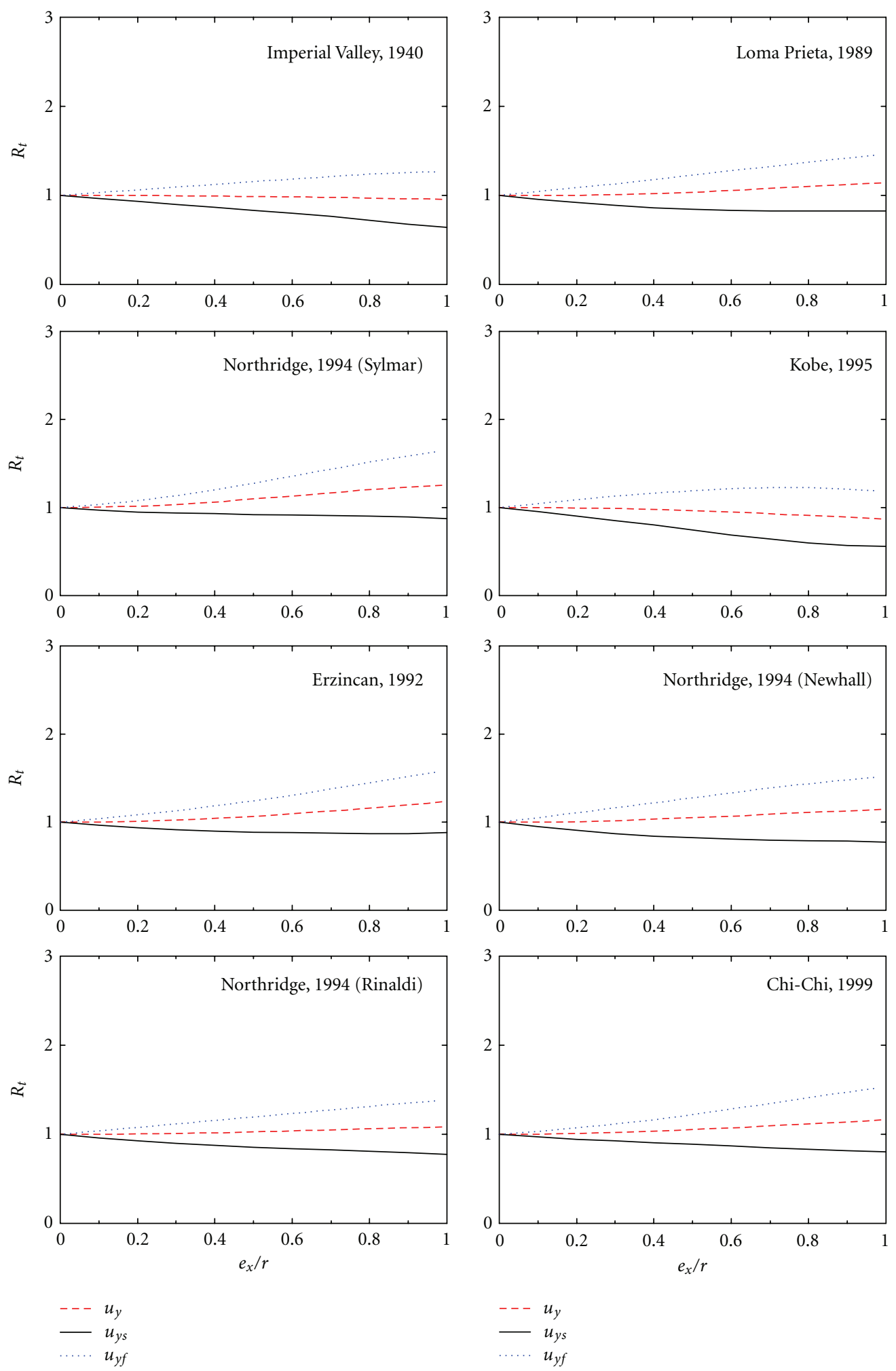

FIGURE 12: Effect of eccentricity on response ratio, $R_{t}$ for various peak displacements $\left(T_{y}=1 \mathrm{~s}, \Omega_{\theta}=2\right)$.

$\Omega_{\theta}=1$, the control forces at stiff edge will be overestimated and at flexible edge that will be underestimated. Moreover, for laterally stiff to laterally flexible systems with $\Omega_{\theta}=2$, the values of ratio, $R_{t}$, for $F_{d s}$ remains slightly less than unity and for $F_{d f}$, it remains slightly more than unity implying that by ignoring the effects of torsional couplings for such systems, the control forces at stiff edge will be overestimated and at flexible edge that will be underestimated. Further, it is important to note that for the systems with $\Omega_{\theta}=0.5,1$ and 2 , the variations in values of ratio, $R_{t}$, for normalized damper 

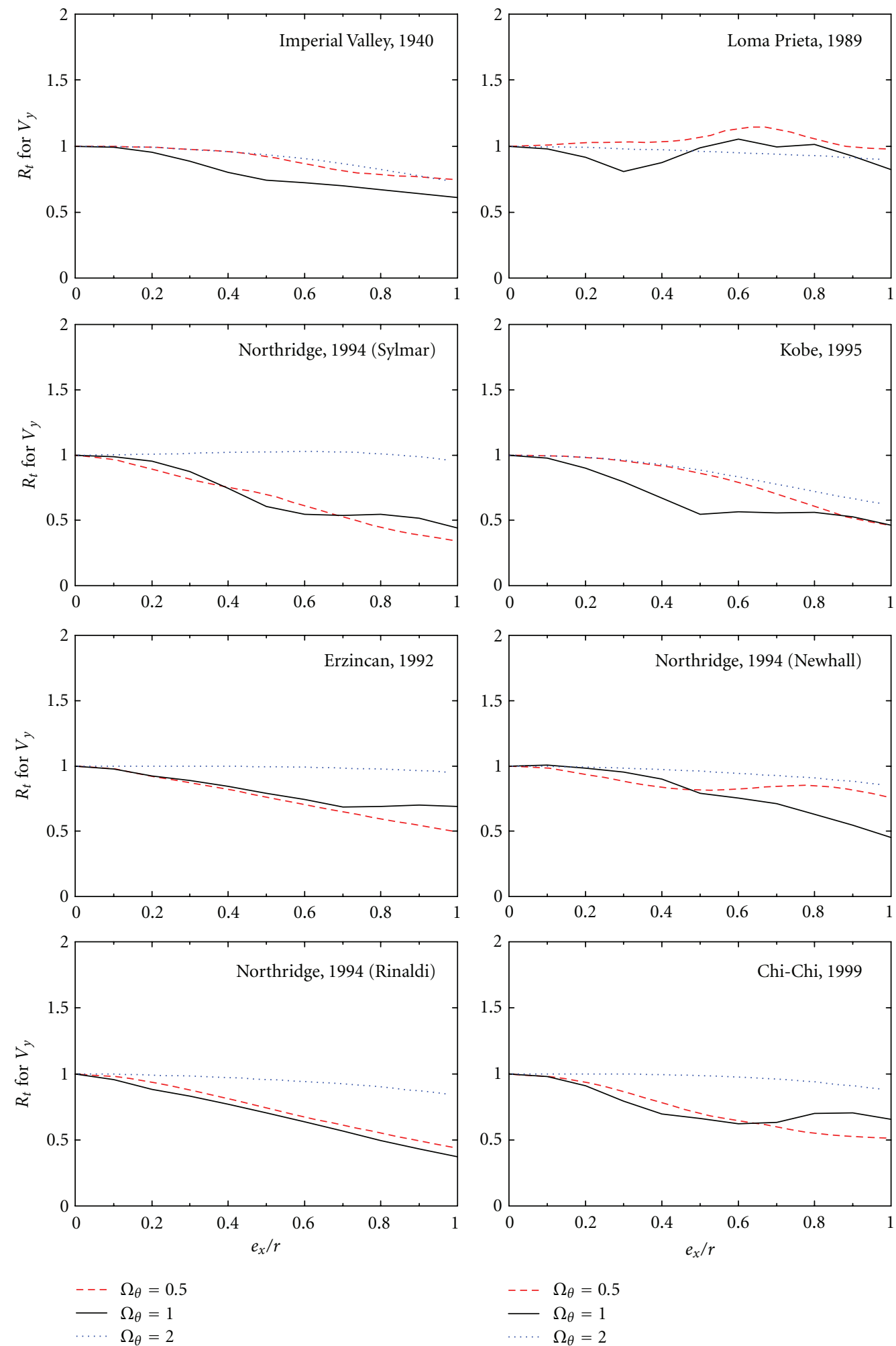

FIGURE 13: Effect of eccentricity on response ratio, $R_{t}$ for peak base shear, $V_{y}\left(T_{y}=1 \mathrm{~s}\right)$.

control forces, $F_{d s}$ and $F_{d f}$, are much more sensitive and significant for laterally stiff systems as compared to laterally flexible systems. Thus, the difference between the damper control forces for asymmetric systems and corresponding symmetric systems is higher for laterally stiff systems as compared to laterally flexible systems and this difference tends to reduce with the increase in lateral flexibility of the superstructure. 

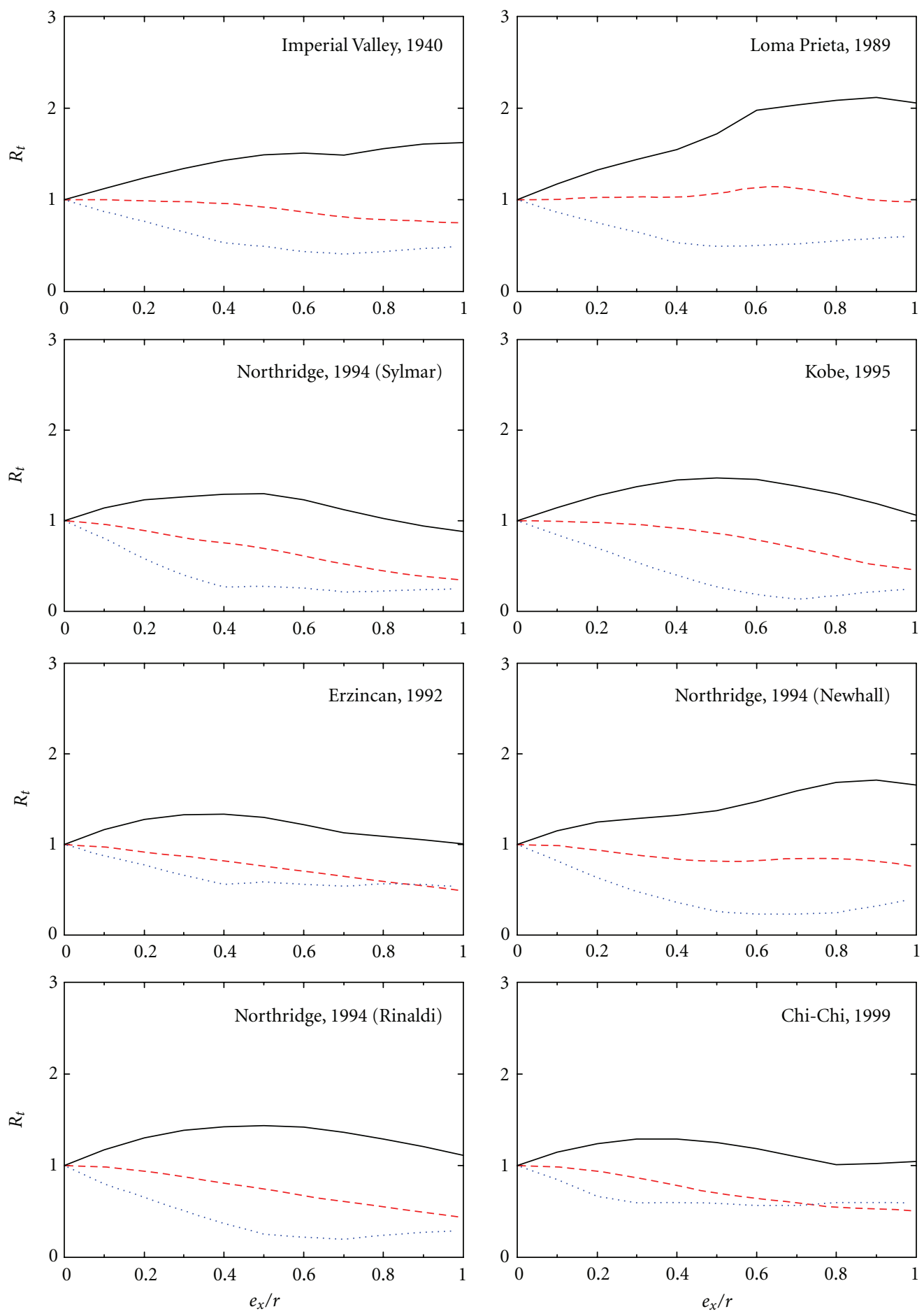

$$
\begin{array}{ll}
--- & \ddot{u}_{y} \\
- & \ddot{u}_{y s} \\
\ldots \ldots & \ddot{u}_{y f}
\end{array}
$$$$
\begin{aligned}
& ---\ddot{u}_{y} \\
& -\ddot{u}_{y s} \\
& \ldots \ldots \cdot \ddot{u}_{y f}
\end{aligned}
$$

FIGURE 14: Effect of eccentricity on response ratio, $R_{t}$ for various peak accelerations $\left(T_{y}=1 \mathrm{~s}, \Omega_{\theta}=0.5\right)$.

In order, to study the effectiveness of semiactive MR dampers with clipped-optimal control algorithm in reducing the coupled responses, the variations of ratio, $R_{e}$ against eccentricity ratio, $e_{x} / r$ for the system with $T_{y}=1$ are shown in Figure 20. The response ratios, $\mathrm{R}_{\mathrm{e}}$, for lateral, torsional, and edge displacements as well as accelerations for different values of $\Omega_{\theta}$ for eight selected earthquakes are obtained and the average trends from these earthquakes are shown in Figure 20. It may be recalled that, the ratio, $R_{e}$ is between the responses of controlled asymmetric system 

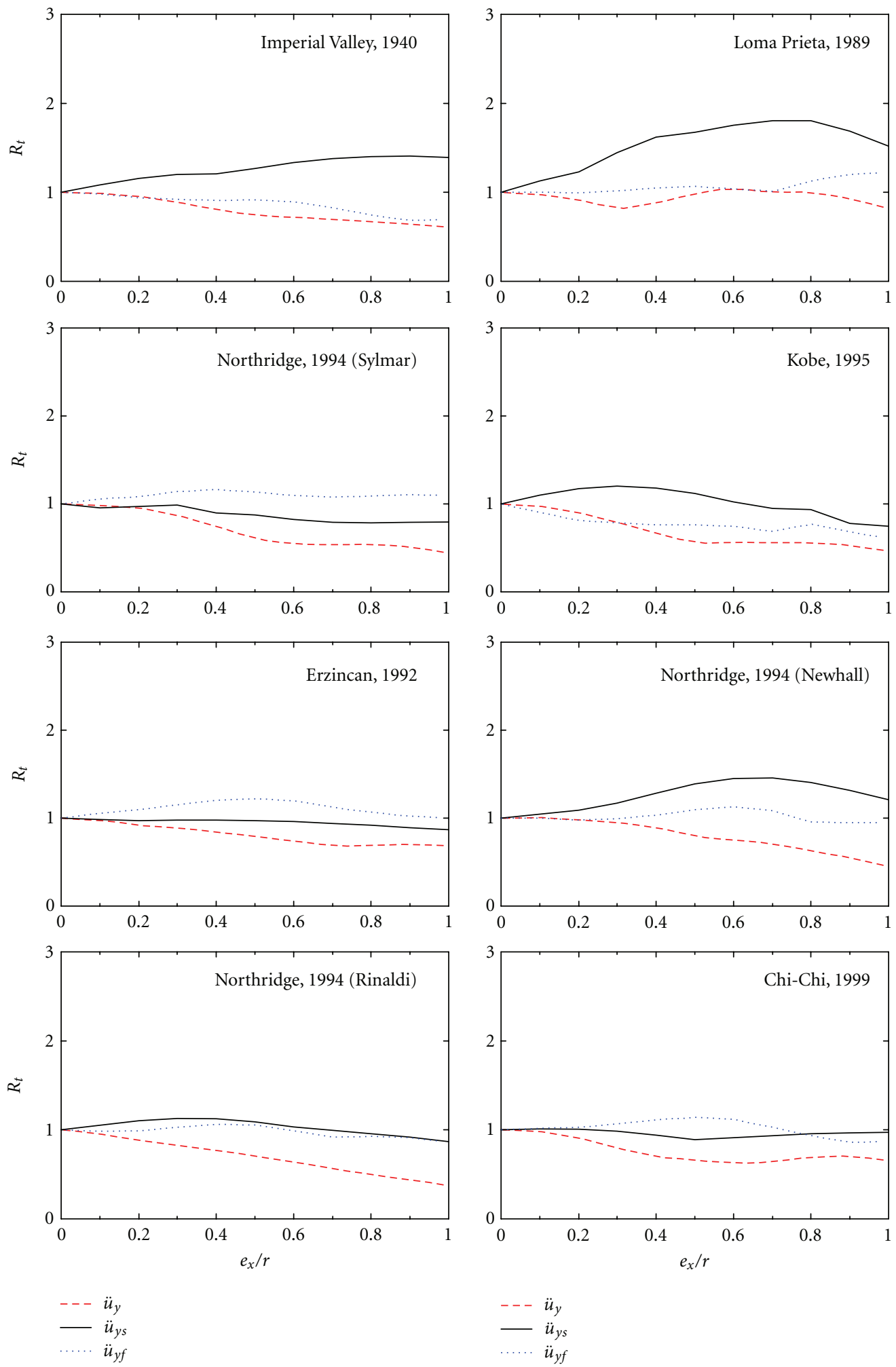

FIGURE 15: Effect of eccentricity on response ratio, $R_{t}$ for various peak accelerations $\left(T_{y}=1 \mathrm{~s}, \Omega_{\theta}=1\right)$.

and corresponding uncontrolled system and its value less than one indicates that the control system is effective in reducing the responses. It can be noticed from the figure that the ratio, $R_{e}$, for lateral, edge, and torsional displacements and accelerations comes out to be less than unity for all considered values of $e_{x} / r$ implying that the semiactive MR dampers using clipped-optimal algorithm is effective in reducing peak lateral-torsional responses. It is further noticed that for strongly coupled system $\left(\Omega_{\theta}=1\right)$, the values of ratio, $R_{e}$, for torsional displacement, $u_{\theta}$, and 

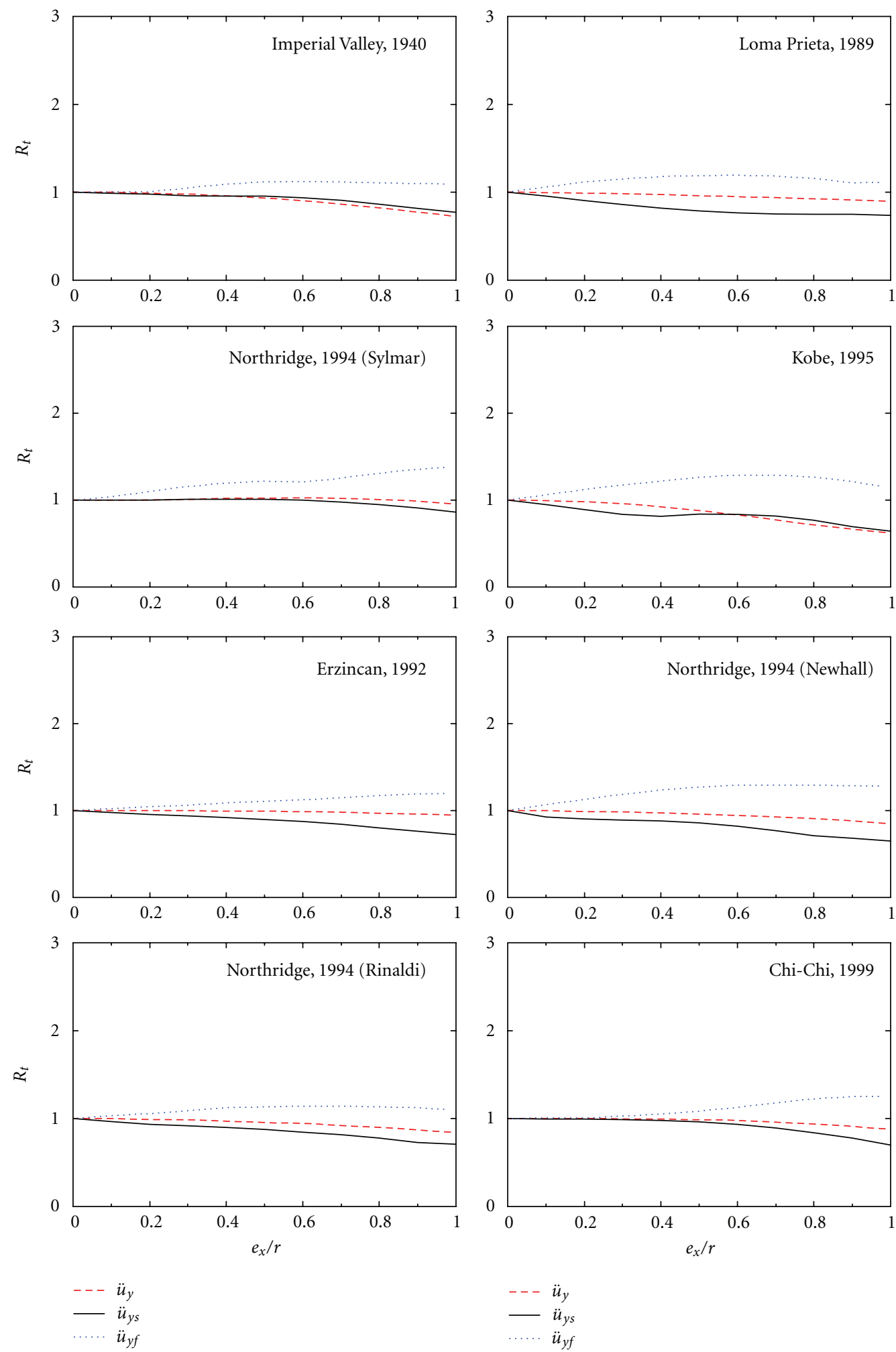

FIGURE 16: Effect of eccentricity on response ratio, $R_{t}$ for various peak accelerations $\left(T_{y}=1 \mathrm{~s}, \Omega_{\theta}=2\right)$.

torsional acceleration, $\ddot{u}_{\theta}$, increases with increase in $e_{x} / r$. This means the effectiveness of control system for controlling $u_{\theta}$ and $\ddot{u}_{\theta}$ reduces for higher eccentricities for such systems. Moreover, for torsionally stiff systems, the values of ratio, $R_{e}$ for all responses quantities remains very less sensitive to the change in $e_{x} / r$. However, for such systems with lower eccentricities ratio, the effectiveness of control system is less in reducing torsional acceleration. Furthermore, for strongly coupled system, the values of $R_{e}$ for torsional displacement and acceleration responses are less than those obtained for 

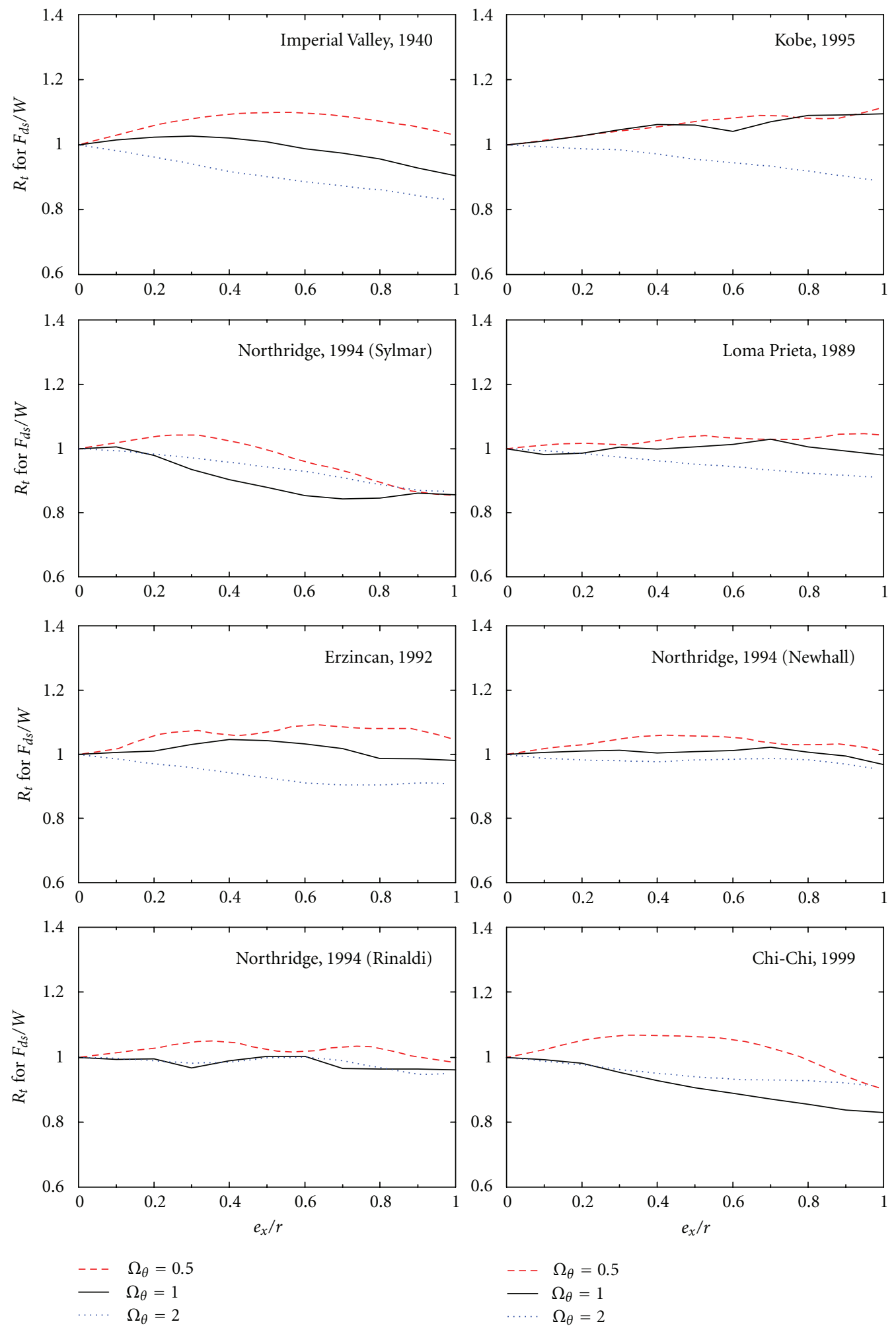

FIGURE 17: Effect of eccentricity on response ratio, $R_{t}$ for normalized stiff edge RMS damper force $\left(T_{y}=1 \mathrm{~s}\right)$.

lateral and edge displacement and acceleration responses for considered range of values of $e_{x} / r$, implying that the implemented control system is more effective for reducing the torsional responses than lateral responses of strongly coupled system. Moreover, the variation in values of ratio,
$R_{e}$ for edge displacements and accelerations strongly depends on values of $e_{x} / r$ for the systems with $\Omega_{\theta}=0.5$ and 1 . Thus, the effectiveness of semiactive control system in reducing the various responses has strong dependence on superstructure eccentricity for torsionally flexible and strongly coupled 

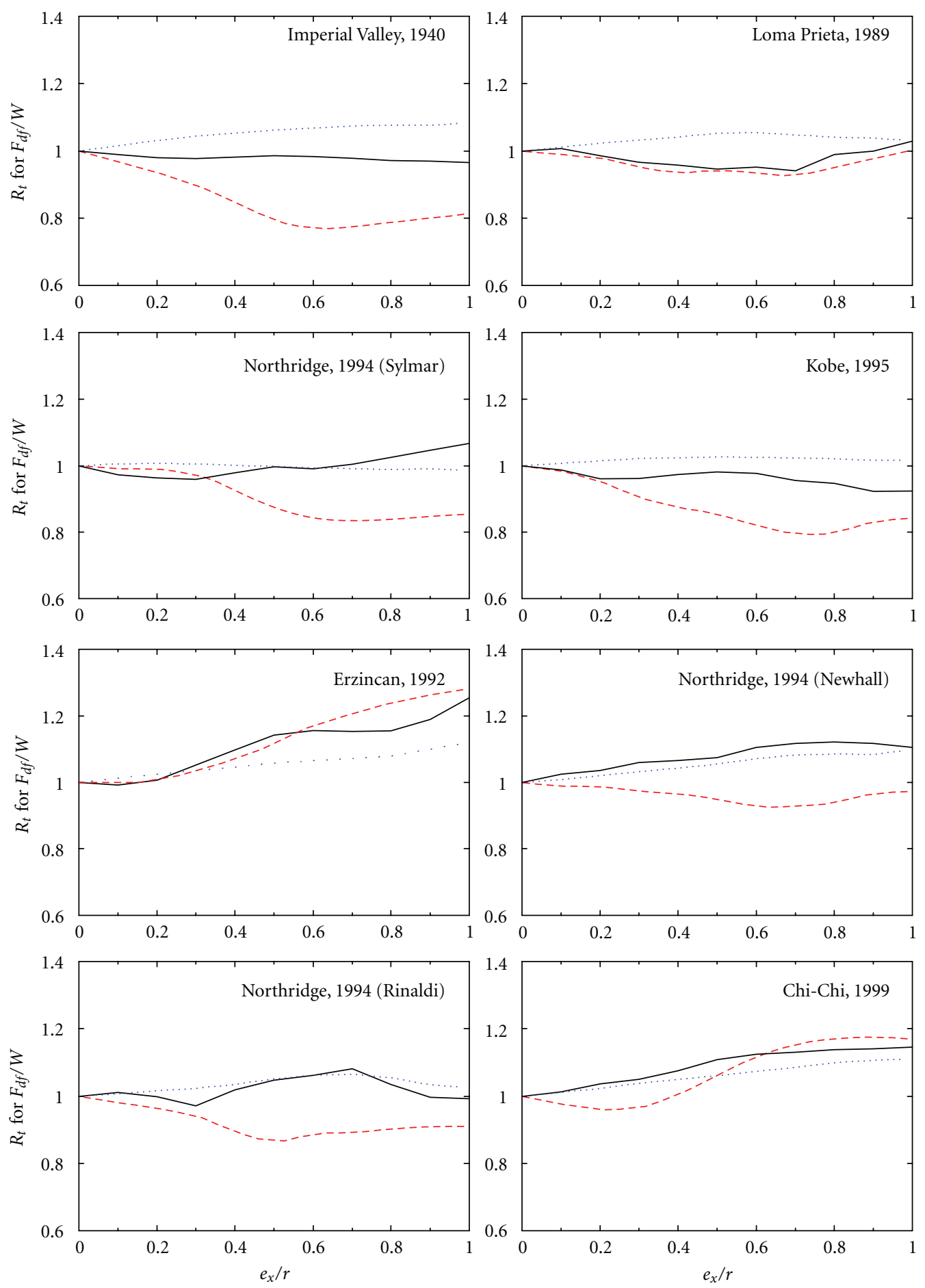

$$
\begin{aligned}
-- & \Omega_{\theta}=0.5 \\
- & \Omega_{\theta}=1 \\
\cdots & \Omega_{\theta}=2
\end{aligned}
$$$$
--\Omega_{\theta}=0.5
$$$$
-\Omega_{\theta}=1
$$

…. $\Omega_{\theta}=2$

FIGURE 18: Effect of eccentricity on response ratio, $R_{t}$ for normalized flexible edge RMS damper force $\left(T_{y}=1 \mathrm{~s}\right)$.

systems and it is very less dependent for torsionally stiff systems.

The investigations carried out in this research paper are based on the idealized single-storey building model with dampers located only at periphery (edges) of the building as it would develop the higher resisting forces. The dampers are assumed to be symmetrically placed in the building. Moreover, from the practical application 

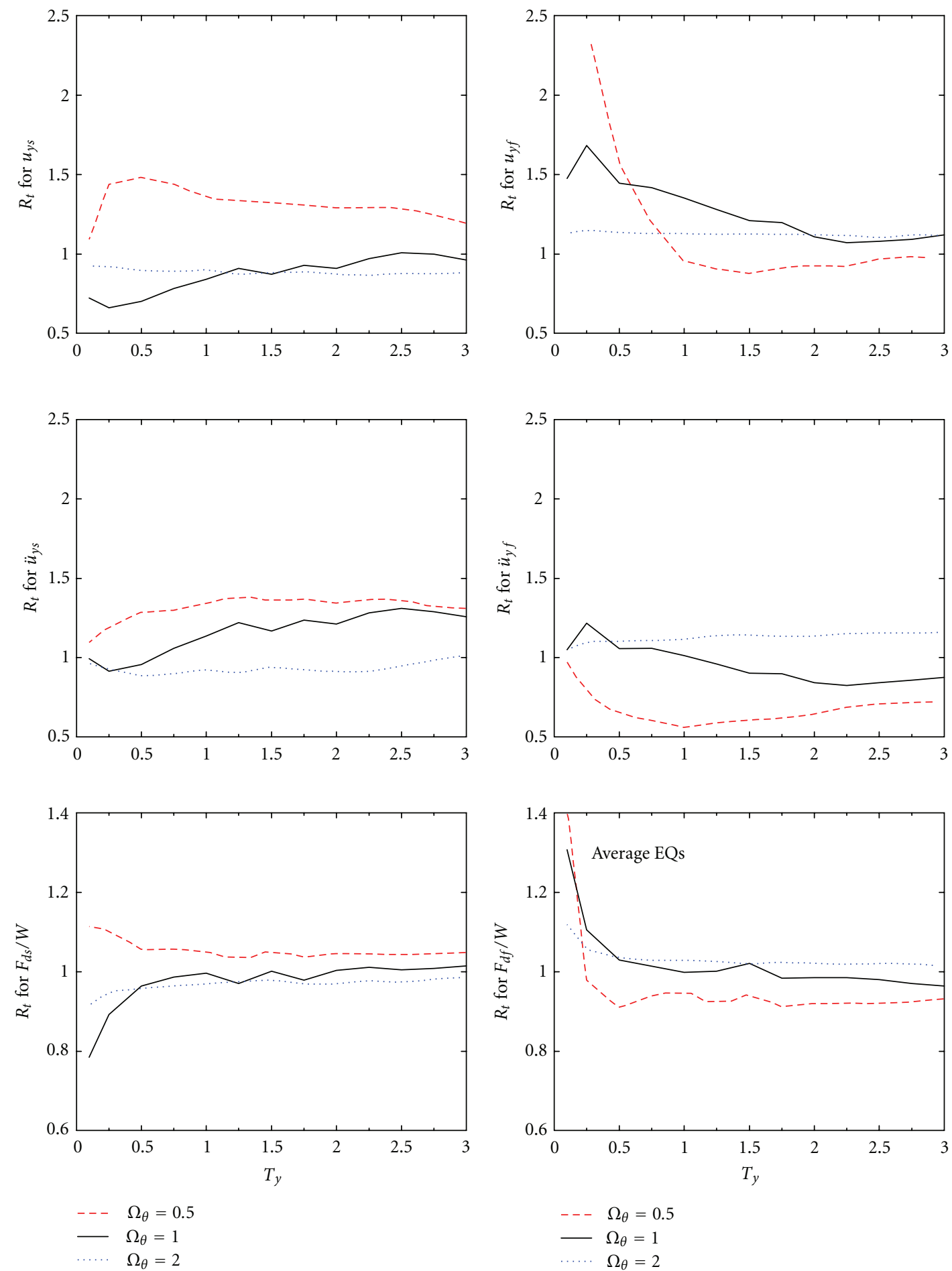

FIgURE 19: Effect of time period, $T_{y}$ on response ratio, $R_{t}$ for peak edge displacements and accelerations and RMS damper forces under average earthquakes $\left(e_{x} / r=0.3\right)$.

point of view also, it shall be convenient to install dampers at the edges of the building to satisfy the functional requirements also. However, it shall be further useful to study the effects of torsional coupling for multistory building with different configuration of dampers in plan and/or in elevation.

\section{Conclusions}

The seismic response of linearly elastic, single-storey, oneway asymmetric building installed with semiactive MR dampers subjected to different earthquake ground motions is investigated. The response is evaluated considering 

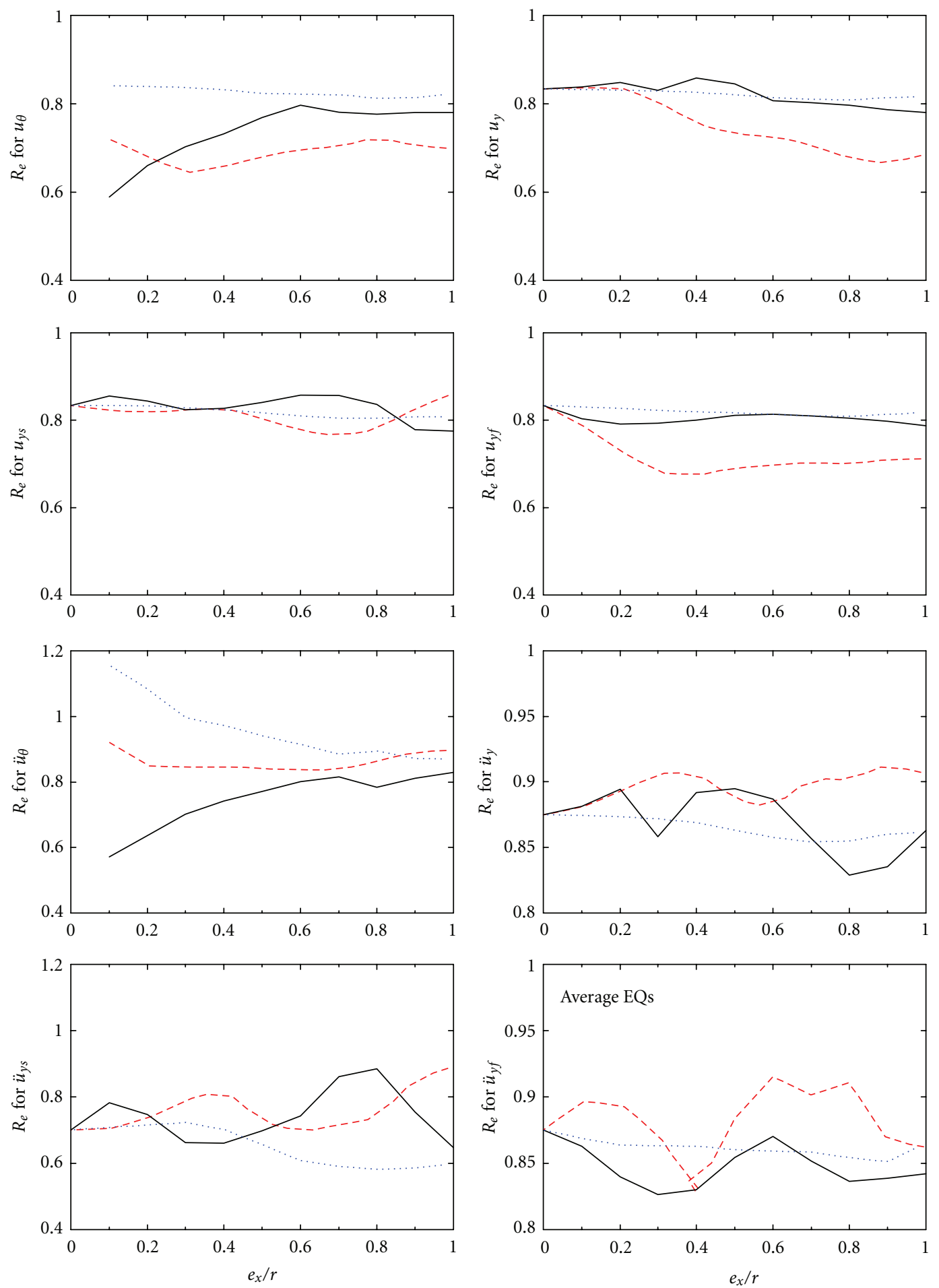

$$
\begin{array}{ll}
-\cdots & \Omega_{\theta}=0.5 \\
- & \Omega_{\theta}=1 \\
\cdots & \Omega_{\theta}=2
\end{array}
$$$$
--\Omega_{\theta}=0.5
$$$$
-\Omega_{\theta}=1
$$$$
\Omega_{\theta}=2
$$

FIgURE 20: Effect of eccentricity on response ratio, $R_{e}$ for various peak response quantities under average earthquakes $\left(T_{y}=1\right)$.

clipped-optimal control algorithm with parametric variations to study the effectiveness of semiactive control system for torsionally coupled system and the influence of important parameters on the effectiveness of semiactive control system for asymmetric systems. The important parameters considered are: eccentricity ratio of superstructure, uncoupled lateral time period, and ratio of uncoupled torsional to lateral frequency. From the trend of the results 
of the present study, the following conclusions can be drawn.

(1) For the semiactive clipped-optimal control algorithm, with little increase in RMS damper forces as compared to passive-off case, the higher or comparable reduction in peak and RMS values of lateral, edge and torsional responses is obtained than those which is obtained by passive-on case.

(2) For torsionally flexible and strongly coupled systems, the effects of torsional coupling can not be neglected while estimating the effectiveness of semiactive control system for asymmetric systems as compared to corresponding symmetric systems in controlling edge displacements.

(3) The difference between the base shear of asymmetric and corresponding symmetric system increases with the increase in eccentricity ratio and it is significant for strongly coupled systems followed by torsionally flexible and torsionally stiff systems.

(4) The effects of torsional coupling are more pronounced for torsionally flexible systems than strongly coupled systems while estimating the effectiveness of semiactive control system for asymmetric systems in controlling lateral and edge accelerations as compared to corresponding symmetric systems.

(5) The effects of torsional coupling on the estimation of control forces significantly depend on superstructure eccentricity and torsional to lateral frequency ratio.

(6) The difference between the damper control forces for asymmetric systems and corresponding symmetric systems is higher for laterally stiff systems as compared to laterally flexible systems and this difference tends to reduce with the increase in lateral flexibility of the superstructure.

(7) The effectiveness of semiactive control system in reducing the various responses has strong dependence on superstructure eccentricity for torsionally flexible and strongly coupled systems and it is very less dependent for torsionally stiff systems.

\section{Notations}

a: Plan dimension of building, parallel to the direction of ground motion

$a_{0}$ and $a_{1}$ : Coefficients for Rayleigh's mass and stiffness proportional damping matrix, respectively

A: $\quad$ System matrix

Ad: Discrete-time system matrix
$A_{m}$ and $n: \quad$ Parameters for MR damper model

$b$ : $\quad$ Plan dimension of building, perpendicular to the direction of ground motion

B: $\quad$ Distribution matrix of control forces

$\mathbf{B}_{\mathrm{d}}$ : $\quad$ Discrete-time counterpart of distribution matrix of control forces

$c_{0 a}$ and $c_{0 b}$ : Parameters for MR damper model

$c_{0 i}$ and $c_{1 i}$ : Parameters for viscous damping observed at large and low velocities, respectively, for $i$ th MR damper model

$c_{1 a}$ and $c_{1 b}$ : Parameters for MR damper model

C: $\quad$ Structural damping matrix of the system

$\mathbf{C}_{m}$ and $\mathbf{D}_{m}$ : Matrices used for measurement equation

$e_{x}$ : $\quad$ Structural (superstructure) eccentricity between centre of mass (CM) and centre of rigidity (CR) of the building system

E: Distribution matrix of excitation forces

$\mathbf{E}_{\mathbf{d}}$ : $\quad$ Discrete-time counterpart of distribution

matrix of excitation forces

f: $\quad$ Damper control force vector

$f_{c i}$ : Desired control force for $i$ th damper

$\mathbf{f}_{c}$ : $\quad$ Desired control force vector

$f_{i}: \quad$ Control force in $i$ th damper

$F_{d f}$ : $\quad$ Control force of damper located at flexible edge of building

$F_{d s}$ : $\quad$ Control force of damper located at stiff edge of building

$g$ : $\quad$ Acceleration due to gravity

$H(\cdot)$ : $\quad$ Heaviside step function

I: $\quad$ Identity matrix

$J$ : $\quad$ Infinite horizon performance index for the design of controller

$k: \quad$ Time step

$k_{0}$ : $\quad$ Stiffness at large velocities of MR damper model

$k_{1}$ : $\quad$ Accumulator stiffness of MR damper model

K: $\quad$ Stiffness matrix of the system

$\mathbf{K}_{g}$ : $\quad$ Gain matrix for the design of controller

$K_{x i}$ : $\quad$ Lateral stiffness of $i$ th column in $x$-direction

$K_{y}: \quad$ Total lateral stiffness of the system in $y$-direction

$K_{y i}$ : $\quad$ Lateral stiffness of $i$ th column in $y$-direction

$K_{\theta r}: \quad$ Torsional stiffness of the system about a vertical axis at the $\mathrm{CR}$

$K_{\theta \theta}: \quad$ Torsional stiffness of the system about a vertical axis at the $\mathrm{CM}$

$l_{a 1}$ : $\quad$ Coordinate of position of the accelerometer 1, located at flexible edge

$l_{a 2}$ : $\quad$ Coordinate of position of the accelerometer 2, located at stiff edge

$\mathbf{L}_{g}$ : $\quad$ Gain matrix for the state estimator

$m$ : $\quad$ Lumped mass of the deck

M: $\quad$ Mass matrix of the system

P: $\quad$ Matrix of algebraic Ricatti equation

$q_{w}$ : $\quad$ Coefficient for weighting matrix, $\mathbf{Q}$ 


\begin{tabular}{|c|c|}
\hline Q: & $\begin{array}{l}\text { Weighting matrix for the vector of } \\
\text { regulated/measured responses }\end{array}$ \\
\hline$r:$ & $\begin{array}{l}\text { Mass radius of gyration about a vertical } \\
\text { axis through CM }\end{array}$ \\
\hline$r_{w}:$ & Coefficient for weighting matrix, $\mathbf{R}$ \\
\hline R: & $\begin{array}{l}\text { Weighting matrix for the vector of control } \\
\text { forces }\end{array}$ \\
\hline$R_{e}:$ & $\begin{array}{l}\text { Response ratio to study the effectiveness of } \\
\text { control system }\end{array}$ \\
\hline$R_{t}:$ & $\begin{array}{l}\text { Response ratio to study the effects of } \\
\text { torsional coupling }\end{array}$ \\
\hline S: & Matrix of algebraic Ricatti equation \\
\hline$T_{y}:$ & Uncoupled lateral time period of system \\
\hline $\mathbf{u}$ and $\dot{\mathbf{u}}:$ & $\begin{array}{l}\text { Displacement and velocity vectors, } \\
\text { respectively }\end{array}$ \\
\hline$u_{d i}:$ & Filtered voltage of $i$ th MR damper \\
\hline$u_{y}:$ & Lateral displacement at $\mathrm{CM}$, in $y$-direction \\
\hline$u_{y f}:$ & Flexible edge displacement \\
\hline$u_{y s}:$ & Stiff edge displacement \\
\hline$u_{\theta}:$ & Torsional displacement, in $\theta$-direction \\
\hline ü: & Acceleration vector \\
\hline$\ddot{\mathbf{u}}_{\mathrm{g}}:$ & Ground acceleration vector \\
\hline$\ddot{u}_{g y}:$ & Ground acceleration in $y$-direction \\
\hline$\ddot{u}_{m f}:$ & $\begin{array}{l}\text { Flexible edge acceleration measured by the } \\
\text { accelerometer }\end{array}$ \\
\hline$\ddot{u}_{m s}:$ & $\begin{array}{l}\text { Stiff edge acceleration measured by the } \\
\text { accelerometer }\end{array}$ \\
\hline v: & Measurement noise vector \\
\hline$v_{i}:$ & $\begin{array}{l}\text { Applied voltage sent to the current driver } \\
\text { of } i \text { th damper }\end{array}$ \\
\hline$V_{\max }:$ & Maximum applied voltage \\
\hline$V_{y}:$ & Base shear \\
\hline$W:$ & Weight of deck \\
\hline$x_{0}:$ & Initial displacement of spring, $k_{1}$ \\
\hline$x_{d i}:$ & Displacement of $i$ th MR damper \\
\hline$x_{i}$ and $y_{i}:$ & $\begin{array}{l}x \text {-coordinate and } y \text {-coordinate distances } \\
\text { of } i \text { th element from CM }\end{array}$ \\
\hline$\dot{x}_{d i}:$ & Velocity of $i$ th MR damper \\
\hline$y_{d i}$ and $\dot{y}_{d i}:$ & $\begin{array}{l}\text { Displacement and velocity at middle plate } \\
\text { of } i \text { th MR damper model }\end{array}$ \\
\hline $\mathbf{y}_{m}:$ & Vector measured responses \\
\hline$z_{i}:$ & Evolutionary variable \\
\hline z: & State vector \\
\hline$\widehat{\mathbf{z}}:$ & Estimated state vector \\
\hline$\alpha_{a}$ and $\alpha_{b}:$ & Parameters for MR damper model \\
\hline & Parameter for $i$ th MR damper model \\
\hline$\beta_{m}$ and $\gamma_{m}$ : & Parameters for MR damper model \\
\hline$\gamma_{g}$ & $\begin{array}{l}\text { Parameter for statistically independent } \\
\text { Gaussian white noise processes }\end{array}$ \\
\hline$\eta:$ & Parameter for MR damper model \\
\hline$\Gamma:$ & Influence coefficient vector \\
\hline$\Delta t:$ & Time interval \\
\hline$\Lambda:$ & Location matrix for control forces \\
\hline$\omega_{y}:$ & Uncoupled lateral frequency of the system \\
\hline$\omega_{\theta}:$ & $\begin{array}{l}\text { Uncoupled torsional frequency of the } \\
\text { system }\end{array}$ \\
\hline$\Omega_{\theta}:$ & $\begin{array}{l}\text { Ratio between uncoupled torsional to } \\
\text { lateral frequency. }\end{array}$ \\
\hline
\end{tabular}

\section{References}

[1] R. Hejal and A. K. Chopra, "Lateral-torsional coupling in earthquake response of frame buildings," Journal of Structural Engineering, vol. 115, no. 4, pp. 852-867, 1989.

[2] R. S. Jangid and T. K. Datta, "Nonlinear response of torsionally coupled base isolated structure," Journal of Structural Engineering, vol. 120, no. 1, pp. 1-22, 1994.

[3] R. S. Jangid and T. K. Datta, "Performance of multiple tuned mass dampers for torsionally coupled system," Earthquake Engineering and Structural Dynamics, vol. 26, no. 3, pp. 307317, 1997.

[4] R. K. Goel, "Effects of supplemental viscous damping on seismic response of asymmetric-plan systems," Earthquake Engineering and Structural Dynamics, vol. 27, no. 2, pp. 125$141,1998$.

[5] V. A. Date and R. S. Jangid, "Seismic response of torsionally coupled structures with active control device," Journal of Structural Control, vol. 8, no. 1, pp. 5-15, 2001.

[6] W. H. Lin and A. K. Chopra, "Asymmetric one-storey elastic systems with non-linear viscous and viscoelastic dampers: simplified analysis and supplemental damping system design," Earthquake Engineering and Structural Dynamics, vol. 32, no. 4, pp. 579-596, 2003.

[7] J. C. de la Llera, J. L. Almazán, and I. J. Vial, “Torsional balance of plan-asymmetric structures with frictional dampers: analytical results," Earthquake Engineering and Structural Dynamics, vol. 34, no. 9, pp. 1089-1108, 2005.

[8] L. Petti and M. De Iuliis, "Torsional seismic response control of asymmetric-plan systems by using viscous dampers," Engineering Structures, vol. 30, no. 11, pp. 3377-3388, 2008.

[9] Y. Chi, M. K. Sain, K. D. Pham, and B. F. Spencer Jr., "Structural control paradigms for an asymmetric building," in Proceedings of the 8th ASCE Specialty Conference on Probabilistic Mechanics and Structural Reliability, University of Notre Dame, July 2000.

[10] O. Yoshida, S. J. Dyke, L. M. Giacosa, and K. Z. Truman, "Experimental verification of torsional response control of asymmetric buildings using MR dampers," Earthquake Engineering and Structural Dynamics, vol. 32, no. 13, pp. 20852105, 2003.

[11] O. Yoshida and S. J. Dyke, "Response control of full-scale irregular buildings using magnetorheological dampers," Journal of Structural Engineering, vol. 131, no. 5, pp. 734-742, 2005.

[12] D. A. Shook, P. N. Roschke, P. Y. Lin, and C. H. Loh, "Semi-active control of a torsionally-responsive structure," Engineering Structures, vol. 31, no. 1, pp. 57-68, 2009.

[13] H. N. Li and X. L. Li, "Experiment and analysis of torsional seismic responses for asymmetric structures with semi-active control by MRdampers," Smart Materials and Structures, vol. 18, no. 7, Article ID 075007, pp. 1-10, 2009.

[14] B. F. Spencer Jr., S. J. Dyke, M. K. Sain, and J. D. Carlson, "Phenomenological model for magnetorheological dampers," Journal of Engineering Mechanics, vol. 123, no. 3, pp. 230-238, 1997.

[15] S. J. Dyke, B. F. Spencer Jr., M. K. Sain, and J. D. Carlson, "Modeling and control of magnetorheological dampers for seismic response reduction," Smart Materials and Structures, vol. 5, no. 5, pp. 565-575, 1996.

[16] G. C. Hart and K. Wong, Structural Dynamics for Structural Engineers, John Wiley \& Sons, New York, NY, USA, 2000.

[17] L. Y. Lu, "Predictive control of seismic structures with semi-active friction dampers," Earthquake Engineering and Structural Dynamics, vol. 33, no. 5, pp. 647-668, 2004. 
[18] L. M. Jansen and S. J. Dyke, "Semiactive control strategies for MR dampers: comparative study," Journal of Engineering Mechanics, vol. 126, no. 8, pp. 795-803, 2000.

[19] H. J. Jung, B. F. Spencer Jr., and I. W. Lee, "Control of seismically excited cable-stayed bridge employing magnetorheological fluid dampers," Journal of Structural Engineering, vol. 129, no. 7, pp. 873-883, 2003.

[20] G. Yang, B. F. Spencer Jr., J. D. Carlson, and M. K. Sain, "Largescale MR fluid dampers: modeling and dynamic performance considerations," Engineering Structures, vol. 24, no. 3, pp. 309323, 2002.

[21] Y. Wang and S. Dyke, "Smart system design for a 3D baseisolated benchmark building," Structural Control and Health Monitoring, vol. 15, no. 7, pp. 939-957, 2008. 

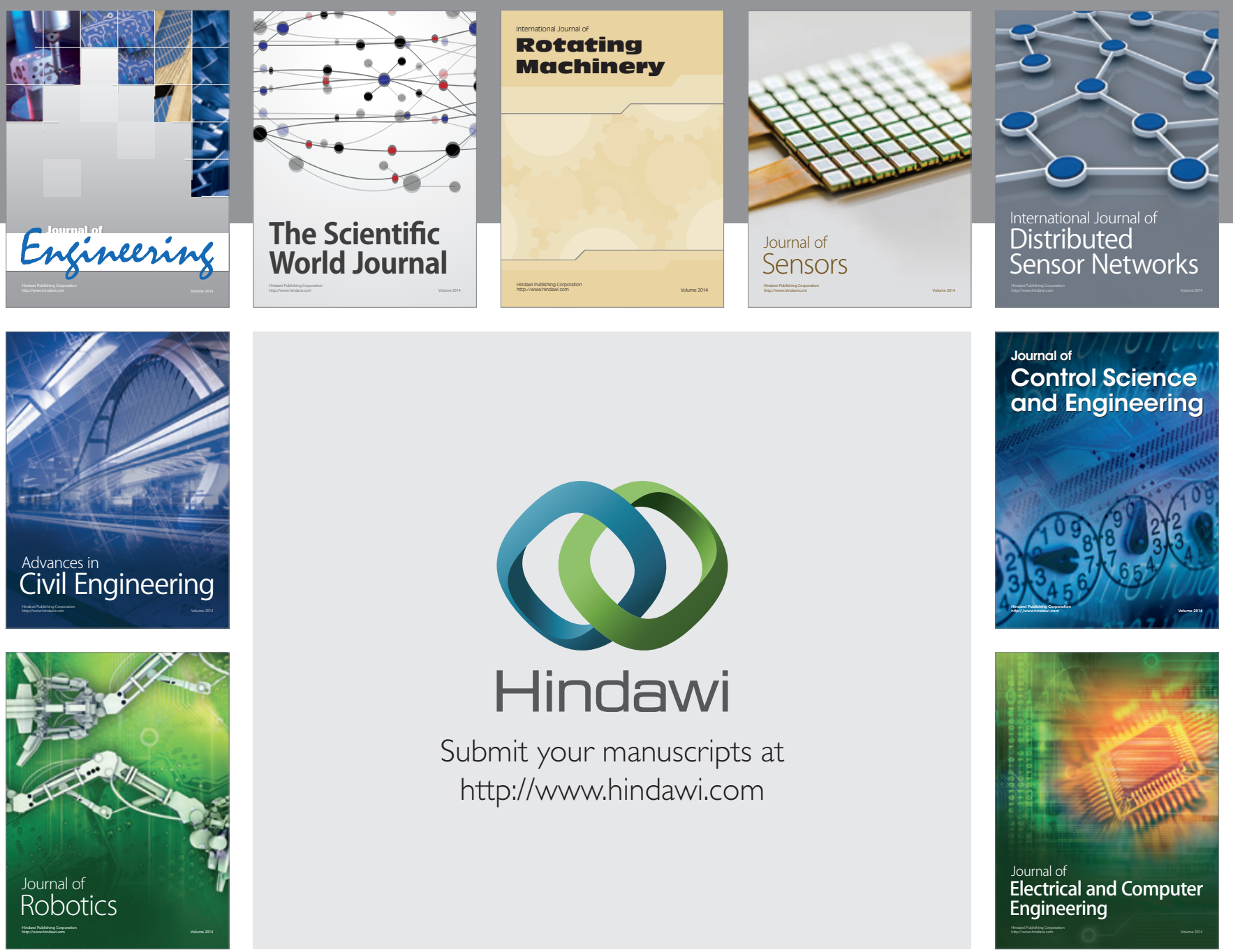

Submit your manuscripts at

http://www.hindawi.com
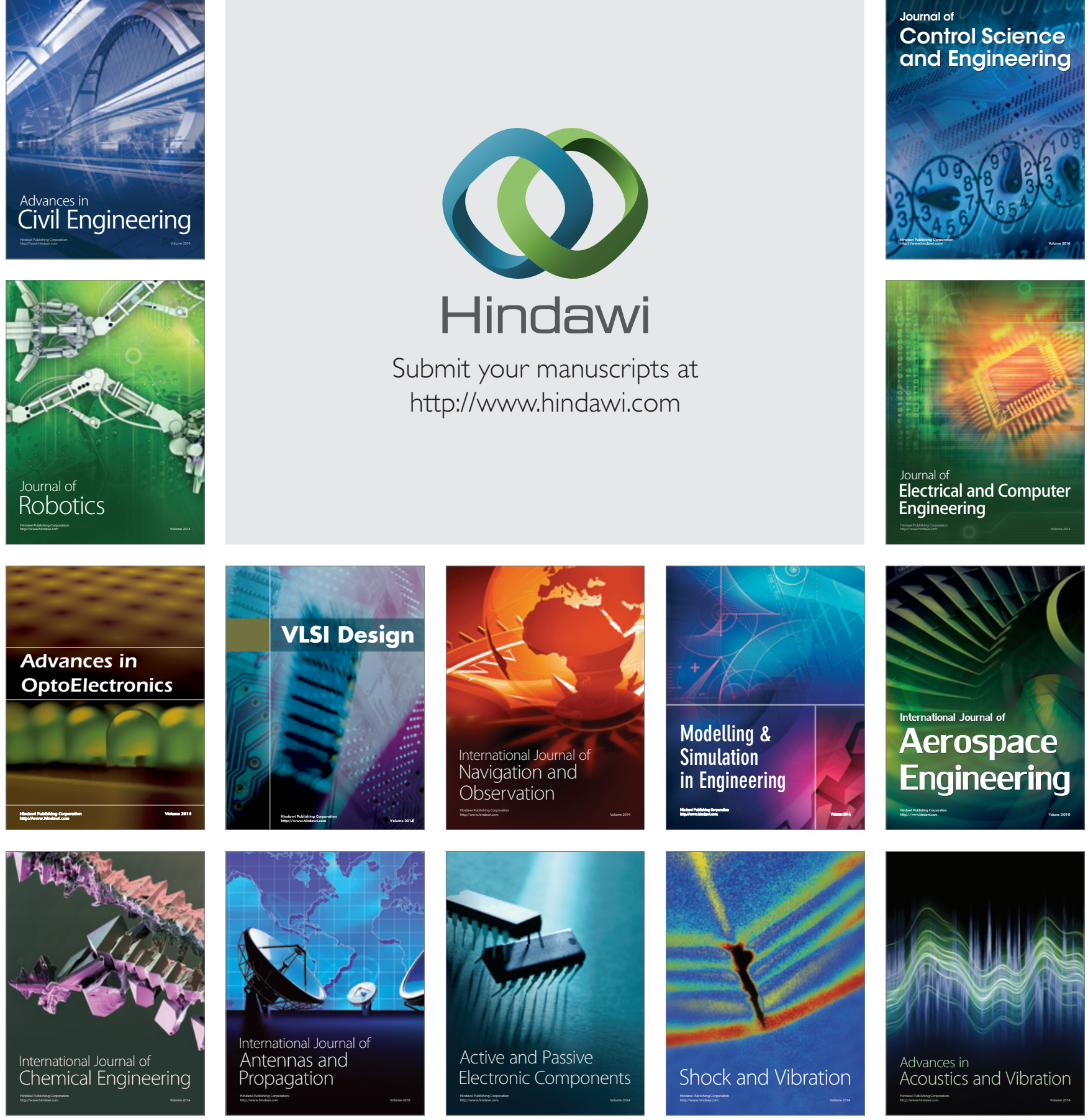